\title{
EFEITO PIEZOELÉtriCo InDUZido EM POLIMERos Sintéticos
}

CARLOS TRES AYALA SUCHICITAL

Dissertação apresentada junto ao Instituto de Física e Química de São Carlos, para obtenção do título de MESTRE EM FísICA APLICA. DA E CIENCIA DOS MATERIAIS.

\section{ORIENTADOR}

Prof. ${ }^{\circ}$ Dr. Robert Lee Zimmerman

DEPARTAMENTO DE FÍSICA E CIÊNCIA DOS MATERIAIS

SÃO CARLOS, SP - BRASIL 
Dedico

a meus pais

\section{e}

à minha esposa 
Este trabalho foi realizado com o apoio financeiro do Progra ma Regional de Desenvolvimento Científico e Tecnológico da OEA, concedido ao Departamento de Física da Universidade Nacional de El Salvador, para o Proje to das Propriedades Físicas dos Materiais Semicondutores e as suas Aplicações 


\section{AGRADECIMENTOS}

Ao Profọ Dr. Robert Lee Zimmerman que orientou-me neste tra balho, pela sua amizade, ensinamentos e disponibilidade.

A Profa. Ethelvina Morillo de Escobar, pela amizade e por encaminhar-me aos meus estudos de Mestrado em Física Aplicada.

Aos Profs. Dra. Maria Cristina Terrile e Dr. Edison Bitten court pelas valiosas discussões e comentārios.

Ao Departamento de Física do IFQSC pelo apoio e carinho que sempre recebi.

Ao Departamento de Engenharia de Materiais da UFSCar, pelo apoio e amizade.

A colega Maria Luiza Rizzi Starr, pela amizade e discussões.

Aos técnicos Josē Roberto Ferro, Rose Mary do Prado e Raimun do Garbelotti Filho, pela Valiosa Cooperação.

A minha esposa pela datilografia deste trabalho, e pela pa ciēncia, apoio e compreensão.

Para eles, os meus sinceros agradecimentos. 
Lista de figuras

Resumo

Abstract

Contribuições Originais

Capítulo I : Introdução

Capitulo II : Noções Gerais

II.1 O Efeito Piezoelétrico

II.2 Piezoeletricidade em Polímeros

II.3 O Efeito Induzido

Capitulo III: Materiais e Método

III.1 Amostras

III.2 Eletrômetro Diferencial

III. 3 Considerações Experimentais

Capitulo IV: Resultados

Capítulo V: Discussão

Capitulo VI: Conclusões

Capítulo VII: Sugestões para Trabalhos Futuros

Apēndice

A.1 Constante do Transdutor 39

A.2 Sistema de Observação da Tensão 


\section{LISTA DE FIGURAS}

II.I - Interação entre os efeitos elásticos e os efeitos elétricos.

II.2 - Transformação de um filme polimërico em eletreto.

II.3 - Representação Vetorial da Tensão e da Polarização.

III.l - Esquema simplificado do aparelho para as medidas simultāneas de condutividade e piezoeletricidade.

III.2 - Diagrama esquemático do sistema para medir a piezoeletricida de inerente e (ou) induzida pelo campo.

III.3 - Esquema do circuito eletrōnico essencial.

III.4 - Esquema do criostato no qual as amostras são colocadas para serem medidas e controlar as condições ambientais de tempera tura e umidade.

III.5 - Sistema de suporte da amostra no criostato.

III.6 - Sistema de aplicação da deformação.

III.7 - Fotografia de amostra pronta para ser colocada no criostato.

III.8 - Criostato para o controle das condições ambientais durante a medição do efeito piezoelētrico de tensão em filmes.

III.9 - Vista do sistema de medição de temperatura e tensão mecãnica.

III.10-Visão geral do eletrōmetro diferencial.

IV.l - Os componentes: real e imaginārio da constante piezoelétrica de Tensão.

IV.2 - Piezoeletricidade induzida pelo campo elétrico.

IV.3 - Os componentes da piezoeletricidade de tensão, $d=d^{\prime}$ - id", para um filme de Poli (Cloreto de Vinila) em várias tempera turas. 
IV.5 - Os componentes da piezoeletricidade da tensão, induzida pelo campo, em uma amostra de Poli (Cloreto de Vinila), depois de um tratamento térmico.

A.1 - Determinação da constante do transdutor. 40

A.2 - Sistema indicador da tensão. 
Construiu-se um apare tho para medir os componentes real e imaginārio da constante piezoelētrica de tensão $d=d^{\prime}-i d^{\prime \prime}$, para filmes po liméricos, com um campo elétrico d.c. externo constante. A razão da constante piezoelétrica e o campo elétrico constante é equivalente a $(\varepsilon+k) s$, onde $\varepsilon \bar{e}$ a constante dielétrica, $k \bar{e}$ a constante de eletro-estrição, e s é a constante elástica de "compliance". A dependência na temperatura, da piezoeletricidade induzida pelo campo, dá uma informação das propriedades elétricas e elāsticas dos polîmeros. Depois de aquecer um filme de Poli (Cloreto de Vinila)até apro ximadamente $950 \mathrm{C}$, seguido de um resfriamento à temperatura ambiental, manten do um campo elétrico externo d.c. constante, observa-se a piezoeletricidade em um campo elētrico d.c. nulo, o qual sugere a introdução de uma polarização residual no filme. 


\section{A B S T R A C T}

An apparatus is devised for measuring the real and imaginary components of the piezoelectric stress constant $d=d^{\prime}-i d^{\prime \prime}$ for polymer films with a d.c. bias field. Electric field induced piezoelectricity is observed for films of several types of polymer. The ratio of the piezoelectric constant to the d.c. bias field gives $(\varepsilon+\kappa) s$, where $\varepsilon$ is the dielectric constant, $k$ is the electrostriction constant, and $s$ is the elastic compliance constant. The temperature dependence of the field induced piezoelectricity gives, therefore, combined information of dielectric and elastic properties of polymers. After heating to about $959 \mathrm{C}$ followed by cooling to room temperature, maintaining a constant d.c. bias on a poly (vinyl chloride) film, piezoelectricity is observed at null d.c. field, which suggests the introduction of a residual polarization in the film. 


\section{CONTRIBUIÇOES ORIGINAIS}

Desenvolvimento de um método preciso e altamente sensível, para a determinação dos coeficientes piezoelétricos e das correntes de condu ção e polarização.

0 método descrito neste trabalho é uma nova maneira de obter informação sobre as propriedades dielétricas e elásticas dos polímeros. 
CAPITULO I

Introdução 


\section{I - INTRODUCATO}

A piezoeletricidade é a propriedade que alguns materiais crista linos ten de apresentar una carga elétrica proporcional a un tensão necáni ca. A palavra piezoeletricidade provén do prefixo grego piezein ${ }^{(1)}$ pressionar, ou seja eletricidade por pressão.

Una melhor definição é dada por Cady (2) "piezoeletricidade ē a pọ larização elétrica produzida pela deformação mecānica em cristais pertencen tes a certas classes, a polarização é proporcional à deformação e a acompanha nas trocas de sinal".

Descoberta por J. e P. Curie (1880), logo se compreendeu que os materiais que apresentam éste fenōmeno devem apresentar o inverso: uma defor mação proporcional a una voltagem aplicada. Este efeito inverso é as vézes confundido com o efeito de eletrostição que é apresentado por todos os ma riais isolantes, muito embora os dois efeitos diferem em aspectos importantes. A deformação piezoelétrica ē, em alguns materiais, geralmente maior em vārias ordens de magnitude que a deformação eletro-estritiva( ${ }^{(1)}$; tambēm é proporcio nal à intensidade do campo elétrico e acompanha a sua troca de sinal, o que não acontece com o efeito eletro-estritivo o, qual é proporcional ao quadrado da intensidade do campo e portanto é independente da sua direção.

o fenōmeno da piezoeletricidade ficou quase esquecido e foi só até a época da 1 â Guerra Mundial que Langevin usou placas de quartzo elétrica mente excitadas, para gerar ondas sonoras na āgua, na detecção submarina. Langevin também usou placas de quartzo para detectar as ondas sonoras; desta maneira ele usou os efeitos piezoelétricos direto e inverso ${ }^{(2)}$.

A partir dos trabalhos de Langevin o interesse na piezoeletricida de aumentou, assim e 1918 Nicholson patenteou um circuito oscilador utilizan do um cristal de sal de Rochelle $\left(\mathrm{NaKC}_{4} \mathrm{H}_{4} \mathrm{O}_{6} \cdot 4 \mathrm{H}_{2} \mathrm{O}\right)$; em 1920 Cady patenteou um 
circuito oscilador que usava um cristal de quartzo cono controlador da fre quência.

A partir dêstes trabalhos pioneiros, o estudo e aplicação do efẹ to piezoelétrico dos materiais cristalinos cresce constantenente.

Shubnikov ${ }^{(3)}$ e Martin(4) com os seus trabalhos em madeiras inicia ram o estudo das propriedades piezoelétricas dos meios anisotrōpicos não cris talinos. Fukada e Yasuda $(5)(6)$ determinaran as propriedades piezoelétricas dos cristais do colageno ao analisar anostras de osso e tendão.

Com os trabalhos de Fukada e outros $(7)(8)(9)$, determinou-se 0 efeito piezoelétrico em polímeros sintāticos. A ele deve-se uma grande parte do trabalho que têm sido publicado em polímeros piezoelétricos sintéticos e naturais. Fukada têm focalizado a sua atenção em polīmeros semi-cristalinos,e adjudica 0 efeito aos cristais polimēricos piezoelétricos submergidos nas re giōes amorfas do polimero(10); e, analisa os componentes das matrizes piezo elétricas, as quais diferem de simetria, dependendo do polímero em particu $\operatorname{lar}(11)$.

A partir de un trabalho de Fukada ${ }^{(12)}$, construiu-se um eletrōne tro diferencial, objetivando a medição das partes real e imagināria do coefi ciente de piezoeletricidade de tensão, e de cuja aplicação surgiram alguns trabalhos $(13)(14)(15)$; e dos quais também esta tese forma parte. 
C A PITULO II

Noções Gerais 


\section{II - NOÇOES GERAIS}

\section{1 Efeito Piezoelétrico}

Alguns cristais quando são submetidos a uma tensão mecānica apresentam um momento de dipolo elétrico, de grandeza proporcional à tensão aplicada. Ao inverter-se o sinal da tensão, o sinal da polarização (P) a acom panha. Este comportamento é o chamado de efeito piezoelétrico direto, e é re presentado pela relação, dado um campo elétrico nulo,

$$
P=d T
$$

Nesta relação o coeficiente $d$ é chamado de coeficiente de piezoe letricidade de tensão, e têm por unidades coulomb/newton, ou metros/volts.

Similarmente, se a êstes cristais aplica-se um campo elétrico $(E)$, a sua forma física apresentarā uma deformação (S) como resultante das fôrças elétricas que agem nos dipolos. Esta deformação acompanha o sinal do campo aplicado. Este comportamento é chamado de efeito piezoelétrico inverso, e é ' representado pela relação, dada uma tensão mecānica nula,

$$
S=d E
$$

Pode-se observar que o coeficiente $d \bar{e}$ dado por,

$$
d=\left(\frac{\partial P}{\partial T}\right)_{E}=\left(\frac{\partial S}{\partial E}\right)_{T}
$$

- qual é uma consequēncia da conservação da energia ${ }^{(16)}$. Assim, $d$ pode obterse medindo a polarização resultante numa amostra em curto $(E=0)$, com uma tensão mecânica aplicada; tambēm, $d$ pode ser obtido medindo a deformação re sultante numa amostra livre $(T=0)$, com um campo elétrico aplicado.

Na Figura II.1, agrupam-se as principais relações entre os fenōme nos eletrostāticos e mecânicos para os cristais piezoelétricos ${ }^{(2)}$. A direção 


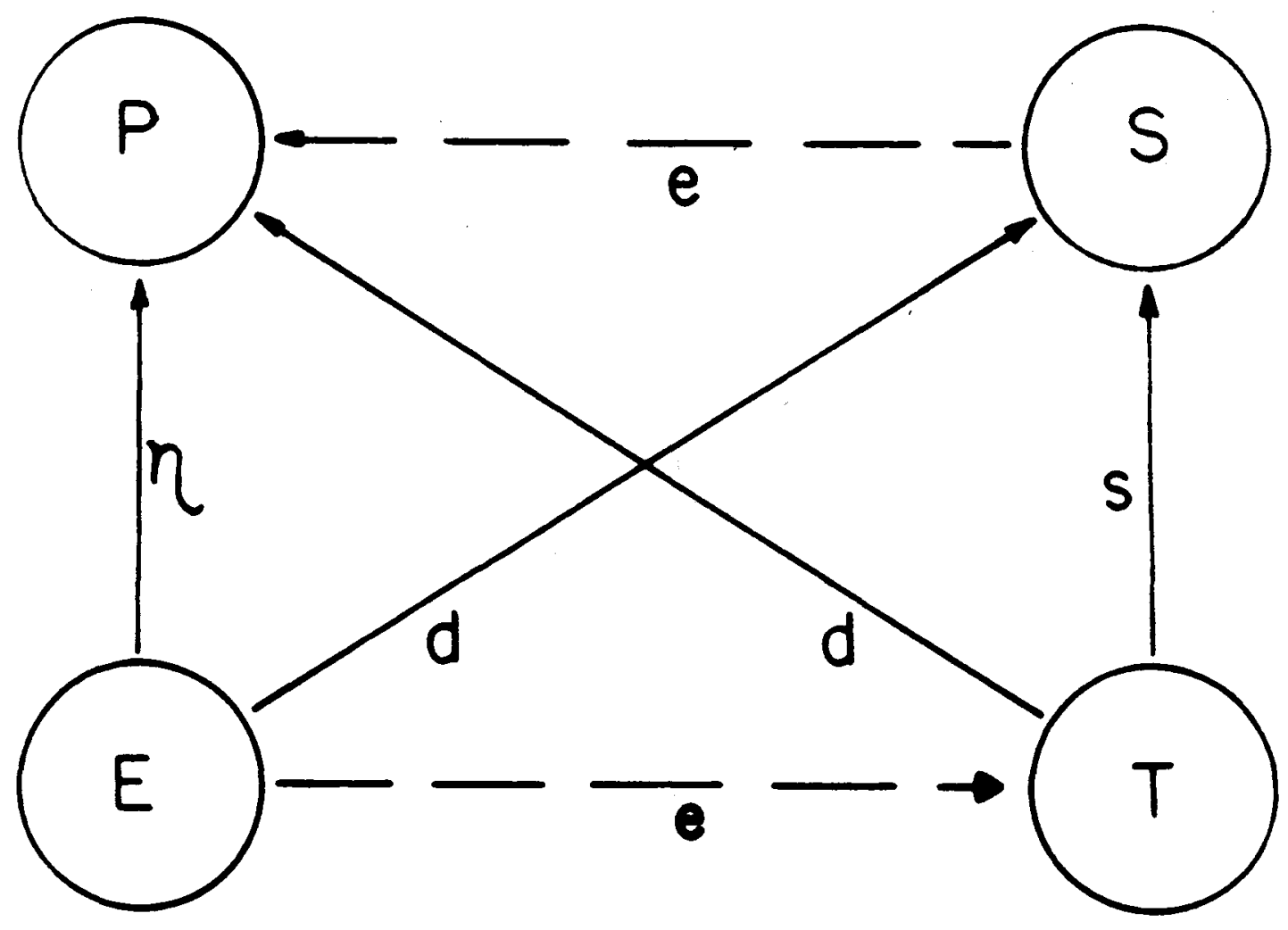

Figura II.I - Interação entre os efeitos elásticos e os efeitos elétricos.

A direção das setas indica a sequência da causa ao efeito. 0 efeito piezoelétrico direto é dado por $P=d T$, e por $P=e S$; consequen temente, o efeito piezoelétrico inverso é dado por $S=d E$, e por $T=-e E$, a relação $P=\eta^{\top} E \bar{e}$ aplicada ao estado mecanicamente livre, e a relação $S=s^{E} T$ é aplicada ao estado elétricamente livre. 0 coeficiente de piezo eletricidade de tensão é dado por $d$, e o coeficiente de piezoeletricidade de deformação é dado por $e$; $\eta \bar{e}$ a susceptibilidade, e s é o mōdulo elástico de "compliance". 
das setas indica a sequência da causa ao efeito. Observa-se que o efeito pie zoelétrico direto pode tambēm ser a consequenncia de uma deformação feita ao cristal, dado um campo elëtrico nulo,

$$
P=e S,
$$

sendo que e é o coeficiente de piezoeletricidade de deformação, e tēm por uni dades coulomb/metro-quadrado $\left(C / \mathrm{m}^{2}\right)$.

Similarmente, o efeito piezoelétrico inverso pode ser uma tensão mecānica resultante de um campo aplicado, dada uma deformação nula,

$$
T=-e E .
$$

Observa-se que o coeficiente $e \bar{e}$ dado por,

$$
\left.e=\left(\frac{\partial P}{\partial S}\right)_{E}=-\frac{\partial T}{\partial E}\right)_{S},
$$

o que significa que e pode obter-se medindo a polarização resultante numa amostra, em curto, enquanto é deformada; ou e pode obter-se pela medição da tensão resultante, numa amostra presa, pela aplicação de um campo elétrico.

As outras duas relações são dadas por,

$$
P=n^{\top} E \text {, }
$$

e por

$$
S=s^{E} T
$$

as quais são aplicadas para os estados mecânica e eletricamente livres $\eta^{\top} e$ $s^{E}$ são a susceptibilidade (Farads/m) para $T=0$, e a constante elástica de "compliance" $\left(\mathrm{m}^{2} / \mathrm{N}\right) \star$ para $E=0$, respectivamente.

* A relação entre a constante elāstica de "compliance" num campo nulo, e a constante elāstica de rigidez (stiffness) num campo elétrico zero ē dada por $s^{E}=1 / c^{E}$. 
Evidentemente, utilizando as equações (1), (4) e (8), a relação entre o coeficiente de piezoeletricidade de tensão e o coeficiente de piezo eletricidade de deformação é dada por,

$$
d=\text { es. }
$$

\section{II.2 Piezoeletricidade em Polímeros}

Desde o descobrimento do efeito piezoelétrico na madeira (17) em 1946, tem-se demonstrado que muitas classes de polímeros são piezoelétricos (18). A constante piezoelétrica da madeira é perto de um vinte-avos da cons tante piezoelétrica de um cristal de quartzo(19). Mas as constantes piezoelé tricas dos eletretos de polímeros mais rescentes, são comparāveis as das cerâa micas piezoelétricas $(20)$.

Muitos filmes de polímeros podem ser transformados em eletretos pela aplicação de um campo elétrico grande, em alta temperatura, seguido de um esfriamento ainda com o campo aplicado (Figura II.2).

Hayakawa e Wada ${ }^{(21)}$ sugerem que esta piezoeletricidade $\bar{e}$ devido ao efeito acoplado da eletro-estrição e a polarização induzida.

E geralmente aceito que a majoria dos filmes de polímeros estão formados por cristais piezoelétricos e uma fase amorfa não piezoelétrica, e que os cristais encontram-se dispersos na fase amorfa; assim, é de se supor que a polarização se atrasa ou se adianta no tempo em relação à tensão mecāni ca aplicada(22) (Figura II.3), da mesma maneira que existe um atraso no tem po entre a tensão mecānica e a deformação em medições viscoelásticas (23). As sim sendo, o módulo piezoelétrico (d) é representado por ${ }^{(10)}$

$$
d^{\prime}=d^{\prime}-i d^{\prime \prime} \text {. }
$$

Na equação 10 , d' representa o componente da polarização que en 


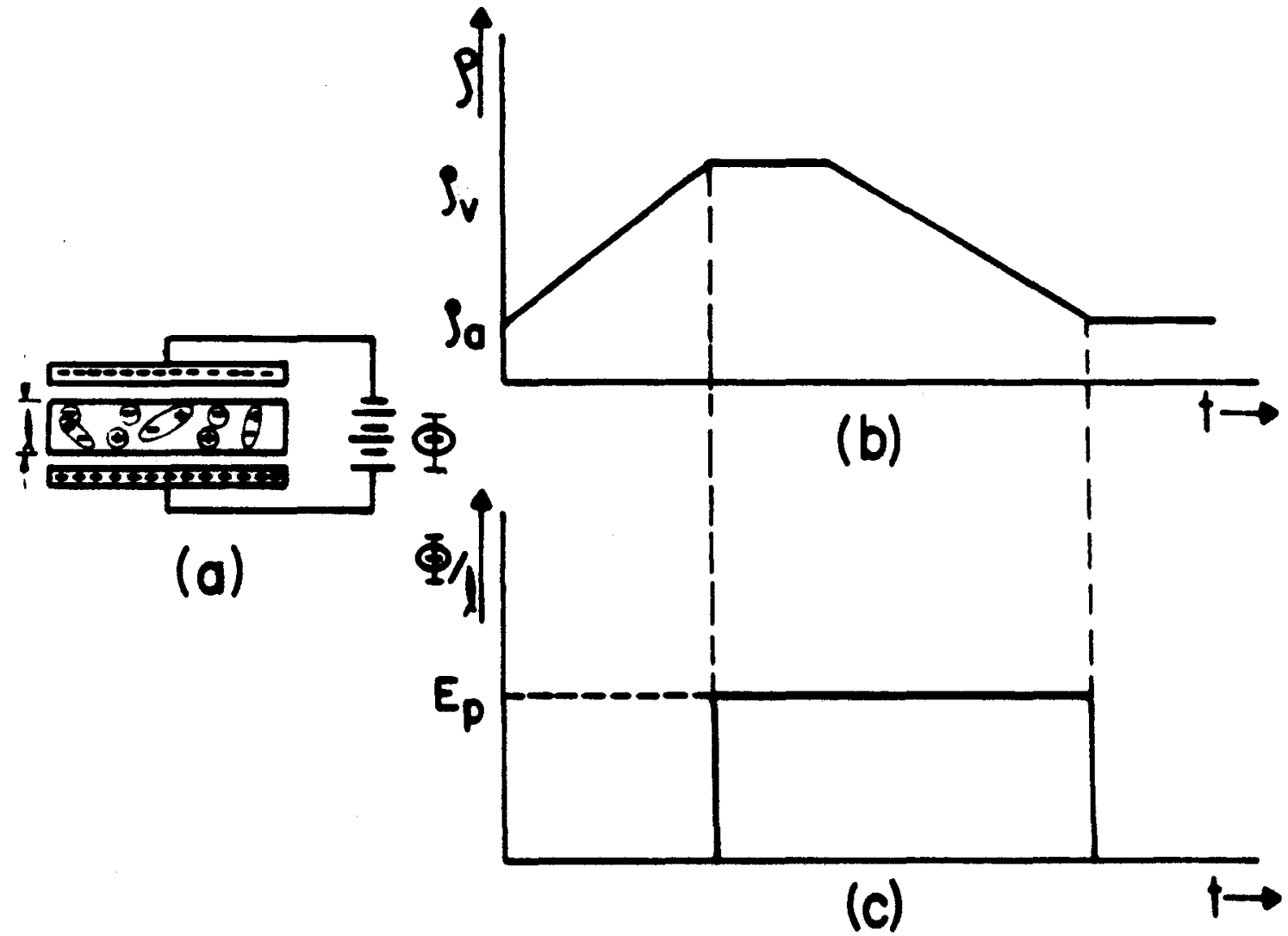

Figura II.2 - Transformação de um filme polimérico, em eletreto

Em (a) uma fatia de um polímero, supostamente amorfo, homogêneo e elasticamente isotrōpico, e com eletrodos depositados nas suas faces, ē sub metido a um tratamento sequencial de temperatura e voltagem, (b) e (c). Em (b) a temperatura ( $\zeta$ ) eleva-se do ambiente até uma temperatura geralmente acima da transição vítrea $\left(\zeta_{v}\right)$ do polímero. Em $(c)$ aplica-se uma voltagem D.C. de vários volts por centímetros de espessura $(\ell)$ do filme. Enquanto se mantém a voltagem no valor $E_{p} \cdot l\left(E_{p}\right.$ é o campo polarizador) a temperatura abaixa-se atē $\zeta_{a}$ e o campo é desligado. 


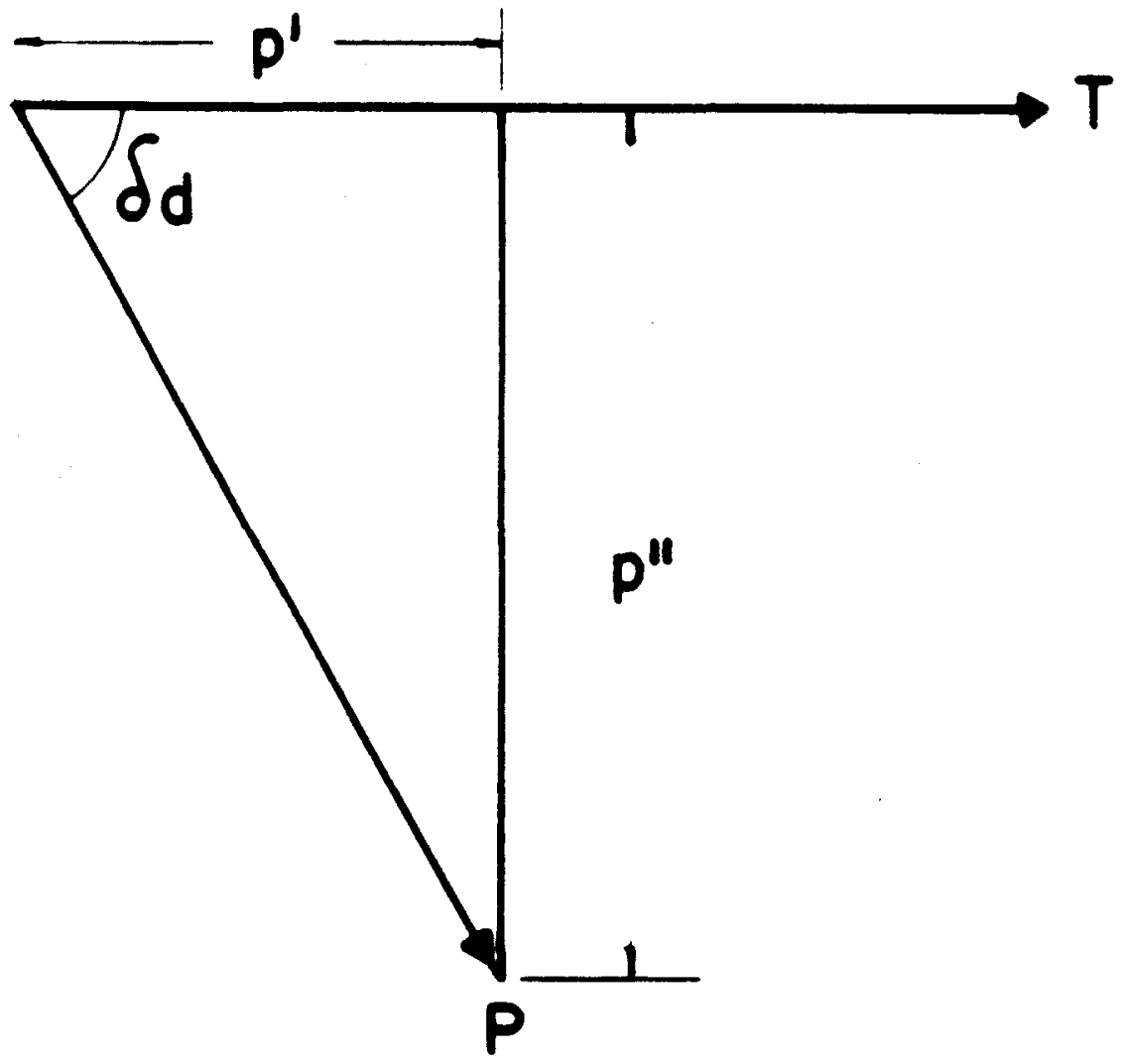

Figura II.3 - Representação Vetorial da Tensão e Polarização

Mostra a tensão mecânica aplicada $(T)$, e a polarização piezoe lé trica $(P)$. Se a tensão aplicada é senoidal, esta pode ser representada por $T=T_{0} \exp$. (iwt); da mesma maneira a polarização pode ser expressada por $P=P_{0} \exp$. (iut $\left.-\delta_{d}\right)$, onde $\delta_{d} \bar{e} 0$ àngulo de fase entre a tensão e a pola rização. A polarização tem dois componentes: $p^{\prime}$ com a mesma fase que $T$, e $p^{\prime \prime}$ que encontra-se $\frac{\pi}{2}$ fora de fase com $T$. Considerando-se $T$ como uma quantidade rea\}, então $p=p^{\prime}-i p^{\prime \prime}$. Consequentemente, $d=d^{\prime}-i d^{\prime \prime}$, sendo que $d^{\prime}=\frac{p^{\prime}}{T}$ e $d^{\prime \prime}=\frac{p^{\prime \prime}}{T}$, e $\tan \delta_{d}=\frac{p^{\prime \prime}}{p^{\prime}}=\frac{d^{\prime \prime}}{d^{\prime}}$. 
contra-se em fase com a tensão, e $d^{\prime \prime}$ representa a componente da polarização que tem um deslocamento de fase de $\frac{\pi}{2}$ com a tensão.

\section{II.3 O Efeito Induzido}

Substāncias amorfas com momentos de dipolo orientados ao acaso, ou aqueles materiais que não tem momentos de dipolo permanentes, não apresen tam piezoeletricidade intrínseca. Embora, considerando-se os efeitos de segun da ordem à indução de dipolos elétricos por um campo externo constante, os ma teriais apresentarão uma piezoeletricidade aparente.

Sabe-se que a piezoeletricidade induzida pelo campo elétrico rela ciona-se ao mesmo efeito quadrātico responsāvel pela eletro-estrição (15).

Considerando-se um material amorfo o qual não apresente efeito eletro-ótico linear (polarização proporcional ao quadrado do campo elétrico), nem piezoeletricidade inerente, a polarização elétrica e a deformação mecāni ca, em função do campo elétrico e a tensão mecānica seriam dadas por,

$$
\begin{aligned}
& p=\eta^{\top} E-2 \gamma E T \\
& s=s^{E_{T}}-\gamma E^{2}
\end{aligned}
$$

onde $n^{\top}$ é a susceptibilidade elétrica na condição de tensão nula, s é o mōdu lo elāstico de compliance na condição de campo nulo, e $\gamma$ é o coeficiente de eletro-estrisão. Assim, $2 y$ pode ser interpretado como a dependência da suscep tibilidade elétrica na tensão.

Consequentemente, para observar a presença da piezoeletricidade aparente pode-se fazer, ou uma medida da polarização elétrica com a aplicação de um campo elétrico constante $\left(E_{0}\right)$ e uma tensão mecānica variāvel $(T)$, ou uma medida da deformação mecānica ( em $T=0$ ) com a superposição de um campo elétrico constante $\left(E_{0}\right)$ e um campo elētrico variāvel (E) muito menor do que 
$E_{0}$, de maneira que o termo $E^{2}$ e linearizado: $\gamma\left(E+E_{0}\right)^{2}=\gamma E_{0}^{2}+2 \gamma E E_{0}$. Considerando as equações (11) e (12), e fazendo

$$
\begin{gathered}
P_{0}=\eta E_{0}, \quad S_{0}=\gamma E_{0}^{2}, \quad e \quad d=2 \gamma E_{0}, \text { temos que } \\
P=P_{0}+d T \\
S=S_{0}+d E .
\end{gathered}
$$

Assim, dé o coeficinete da piezoeletricidade induzida pelo campo elétrico.

Algumas observações na piezoeletricidade induzida pelo campo elé trico e o método de medição, serão apresentados no capítulo a seguir. 
C A P I TULO III

Materiais e Método 


\section{II - MATERIAIS E METODO}

\section{III.I Amostras}

Filmes de polimeros comerciais de espessura constante foram obti dos, e eletrodos de aluminio foram depositados a vácuo neles, com a ajuda de uma māscara metālica, e as amostras assim cortadas. 0 tamanho aproximado das amostras foi de $(50 \times 8 \times 0,05) \mathrm{mm}$. Tomou-se cuidado para que os eletrodos de positados na amostra cobrissem a ärea das fases completamente, e fizeram-se cortes adequados para o encaixe nos suportes.

Desta maneira prepararam-se amostras dos seguintes filmes comer ciais: Poli (Fluoreto de Vinilideno) ( PVF $_{2}$ ), Poli (Fluoreto de Vinila) (PVF), Poli (Cloreto de Vinila) (PVC), Poli (Tetra Fluoroetileno) (Teflon), Poliamida (Nylon 11), e Polietileno de alta densidade (HDPE).

As amostras de materiais polares, foram termicamente tratadas em curto circuito, em temperaturas adequadas $\left(\simeq 95^{\circ} \mathrm{C}\right)$, para remover os efeitos piezoelētricos intrinsecos.

\section{III.2 Ele trömetro Diferencial}

Para a determinação da constante piezoelétrica se fez uso de um eletrômetro diferencial. O aparelho é baseado numa idéia de Eiichi Fukada (12) e foi completamente construido no IFSQ. Parte deste trabalho è aqui apresenta do. Cosc

0 método depende do cancelamento da carga de polarização piezoelétrica, com uma carga determinada por um potencial conhecido e aplicado atravēs de uma capacitância e de uma resistência também conhecidas, e o nulo é detectá do. O cancelamento da tensão elētrica gerada pela carga da polarização piezo elétrica implica a condição de campo elétrico nulo na amostra durante todo o 
ciclo da força aplicada. Condição que é essencial na determinação dos coefí cientes piezoelétricos de tensão (eqs. 1, e 4). Este sistema também permite medir amostras com resistēncia elétrica relativamente baixa, mantendo a condi ção de ausência de corrente de condução, importante nas situações de medição de amostras hidratadas

A Figura III.1, mostra um diagrama simplificado do aparelho para medir simultāneamente os efeitos piezoelétricos de tensão e a condutividade $\underline{e}$ Tétrica. Logo na figura III.2, pode-se ver um diagrama esquemático mais com pleto do sistema. Uma tensão mecânica senoidal é aplicada longitudinalmente a um filme numa frequēncia constante por meio de um transdutor eletromagnéti co. A corrente na espiral do transdutor indica a magnitude da förça deformati va na amostra (Apêndice 1). Para poder cancelar a voltagem piezoelétrica no filme deriva-se, da corrente impulssora, uma voltagem canceladora a qual é fornecida à amostra atravēs de uma capacitāncia (C) e uma resistēncia (R). A primeira cancela o componente da voltagem piezoelétrica em fase com a força, e a segunda cancela o componente da voltagem piezoelétrica $90^{\circ}$ fora de fase. A voltagem que a amostra gera é conduzida a retificadores sincronos, e que tem uma voltagem de referēncia em fase e uma voltagem de referéncia $90^{\circ}$ fora de fase com a corrente impulssora. Pelo ajuste de dois potenciómetros ( $\theta^{\prime} \mathrm{e} \theta^{\prime \prime}$ ) se abserva nos galvanōmetros (GA) O ponto nulo nas voltagens de saída dos re tificadores sincronos.

Entretanto se fazem as determinações piezoelétricas a amostra en contra-se sujeita a um potencial constante Vo aplicado através de um filtro. 0 nanoamperimetro (NA) permite determinar simultāneamente com as medidas pie zoelétricas, a condutividade e correntes de polarização e despolarização na amostra.

A Figura III.3, mostra componentes do circuito eletronico essen cial. Os circuitos integrados são empregados como amplificadores e como reti 


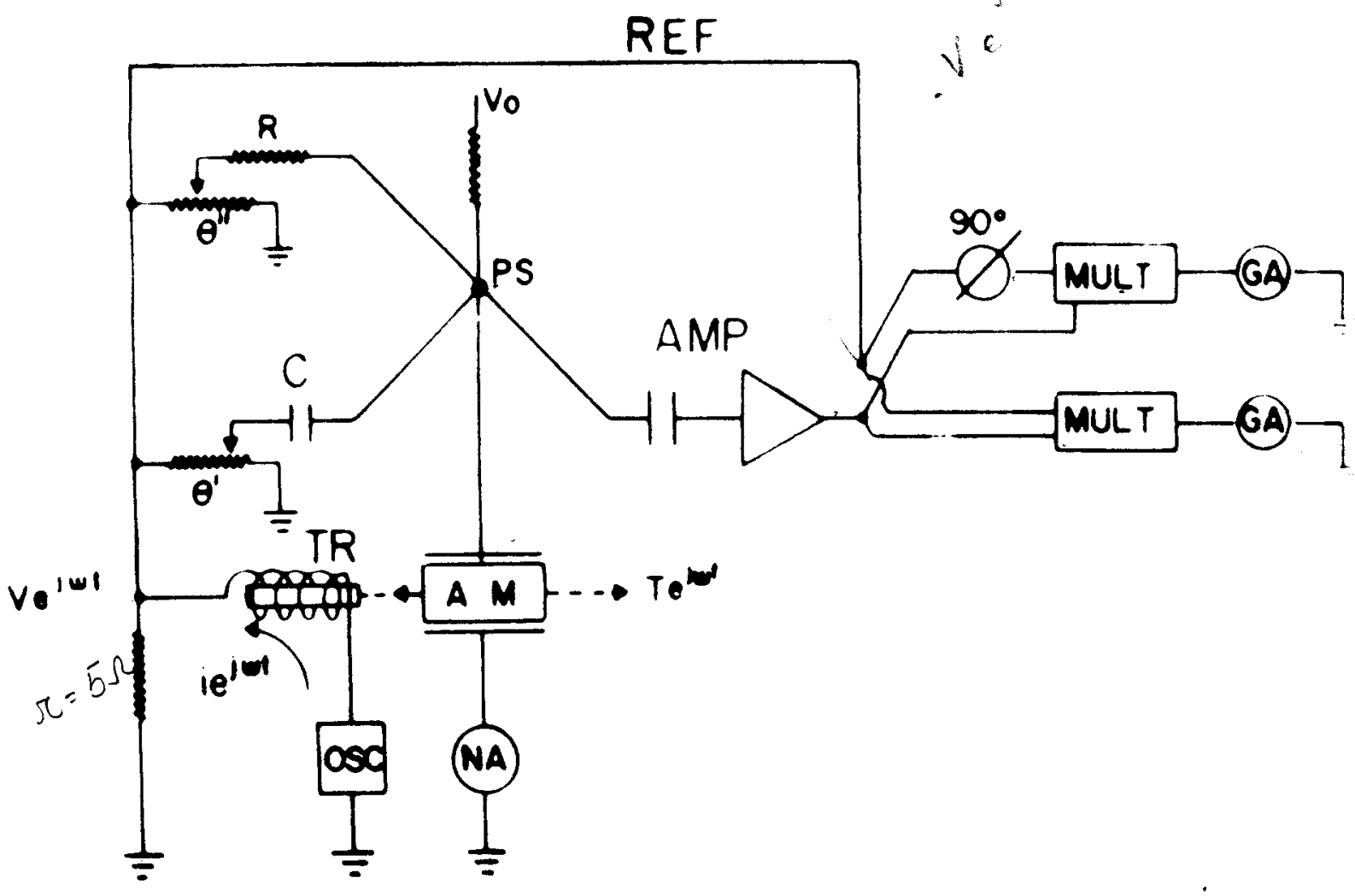

Figura III.l - Esquema simplificado do aparelho para as medidas simultãneas de condutividade e piezoeletricidade.

Para uma indicação nula nos galvanōmetros $(G A)$, os potenciōme tros $\left(\theta^{\prime}\right.$ e $\left.\theta^{\prime \prime}\right)$ indicam os componentes real e imaginārio do coeficiente piezo elētrico de tensão $\left(d=d^{\prime}-i d^{\prime \prime}\right)$. Simultaneamente, o eletrōmetro (NA) mede a corrente de condução e a polarização induzidas pelo campo elétrico, ou, com a fonte $V_{0}$ ligada a terra, mede a corrente de despolarização da amostra. 


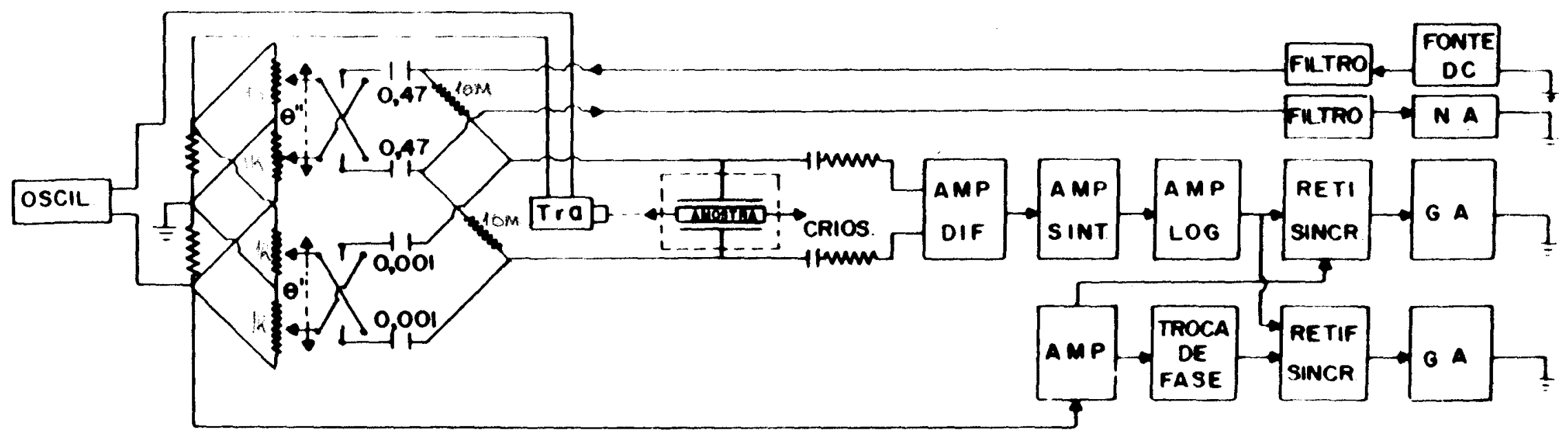

Figura III.2 
Figura III.2 - Diagrama esquemático do eletrōmetro diferencial para medir a piezoeletricidade inerente e (ou) induzida pelo campo.

Com a indicação de nulo nos galvanômetros $(G A)$, os potenciōmetros dão uma leitura dos componentes real e imagināria da constante piezoelé trica de deformação $\left(d=d^{\prime}-i d^{\prime \prime}\right)$. Simultāneamente o nanoamperīmetro (NA) me de a condução induzida pelo campo e a corrente de polarização; ou mede a cor rente de despolarização com a fonte DC aterrada. 


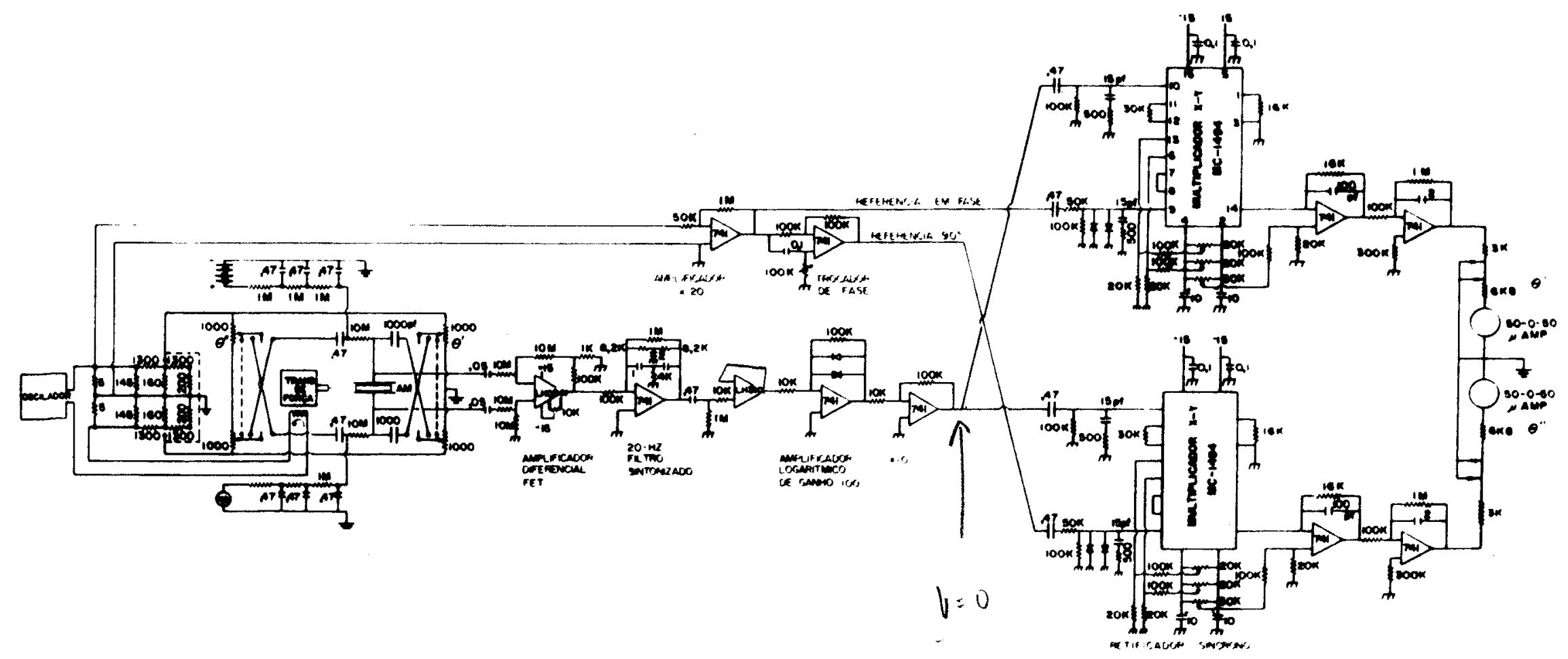

Figura III.3 
Figura III.3 - Esquema do circuito eletrōnico essencial.

A tensão de cancelamento, do sinal piezoelétrico gerado amostra, é obtida atravēs de malhas formadas por chaves, potenciōmetros, resi $\underline{s}$ tências e capacitores. O sinal é amplificado por amplificadores diferenciais, e por amplificadores estāveis sintonizados. Os componentes $(09$ e 900 fora de fase) são recebidos pelos multiplicadores $x y$ respectivos, e comparados com 0 sinal de referēncia obtido da tensão ao transdutor de força. 0 produto $\bar{e}$ inte grado tal que somente o sinal com a frequéncia $(20 \mathrm{~Hz})$ do oscilador, que ali menta o transdutor, tem um componente não nulo. o erro é anulado por meio dos potenciōmetros. 
ficadores sincronos. A tensão de cancelamento do sinal piezoelétrico gerado na amostras, é obtida atravēs de malhas formadas por chaves, potenciōmetros, resistēncias e capacitores. A amplificação do erro é primeiramente feita por um amplificador diferencial de transistores FET, e logo por uma série de am plificadores estáveis sintonizados. 0 sinal é dirigido a dois multiplicadores xy, um para cada componente (0̣ ou 900 em relação à referéncia) dela que mu tiplicam o erro com o sinal de referēncia obtido da tensão aplicada ao trans dutor de força. O produto é convertido em uma tensão e integrado tal que so mente o sinal com a frequência $(20 \mathrm{~Hz})$ do oscilador, que alimenta o transdu tor, tem um componente não-nulo. 0 erro pode ser anulado por meio dos poten ciōmetros, um para cada fase deste.

A Figura III.4, mostra um esquema do criostato no qual as amos tras são colocadas para serem medidas, e por meio do qual podem-se variar as condições ambientais de temperatura e umidade. Consiste, essencialmente em trēs caixas metālicas concēntricas. A caixa externa é eletricamente isolada das outras, e serve de retentor ao isolante térmico. A caixa intermediäria contém o elemento aquecedor e serve de reservatörio para o líquido refrigeran te. A caixa interna é a càmara da amostra. A monitoria da temperatura é feita por meio de um termopar de cobre-constantan e um registrador $x-y$ ou um mili voltimetro.

A amostra já cortada no tamanho adequado e com os eletrodos depo sitados nela, é colocada no criostato e presa no lugar por dois braços de Te flon e porcas metálicas, as quais estão em contato elétrico com os eletrodos na amostra e o resto da aparelhagem. Como pode-se ver na Figura III.5, estes braços são concêntricos, e não entram em contato com o criostato.

A tensão deformativa constante na amostra é aplicada por meio de um parafuso metālico, no qual encaixa-se um dos braços de Teflon, e tem um passo conhecido $(0.11 \mathrm{~cm})$, como pode-se ver na Figura III.6; o outro braço de 

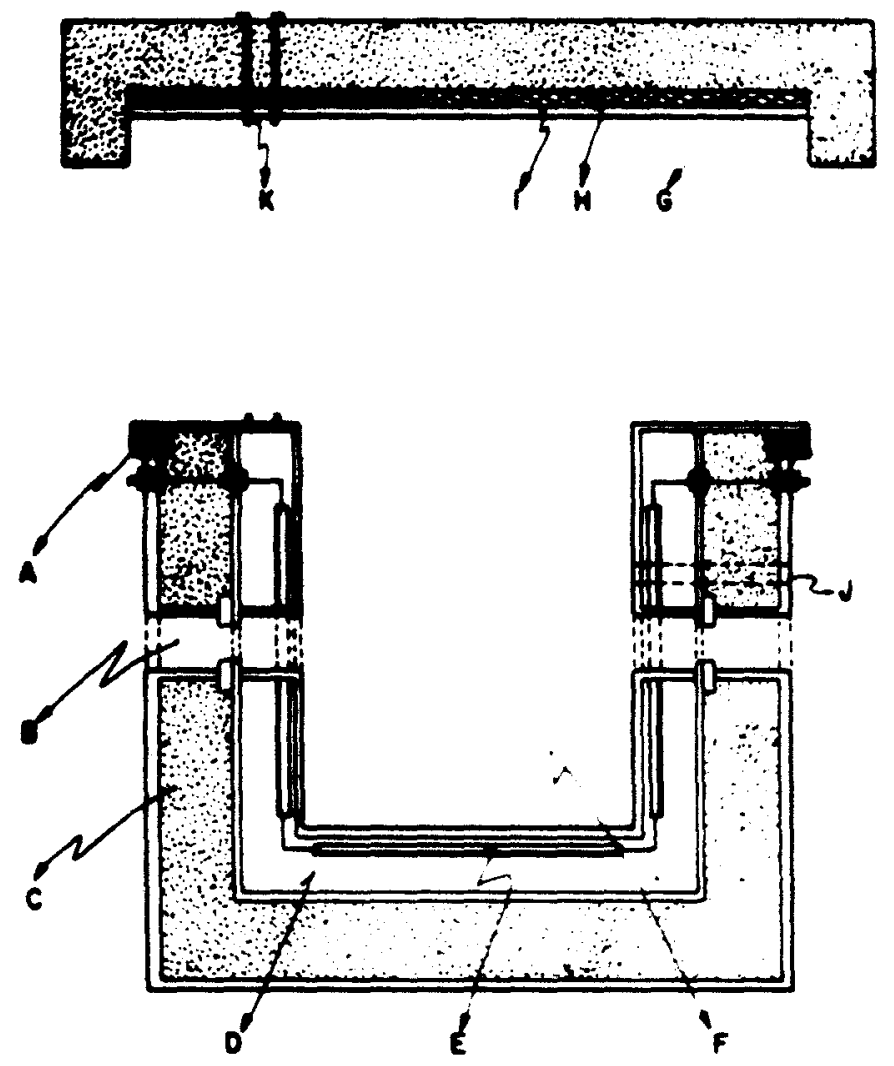

Figura III.4 - Esquema do criostato no qual as amostras são colocadas para se rem medidas, e controlar as condições ambientais de temperatu ra e umidade.

0 criostato é formado por très caixas concēntricas e é consti tuido das seguintes partes: A) Isolante elétrico; B) Entrada dos suportes que prendem a amostra; C) Isolante térmico; D) Espaço para līquido refrigerador; E) Elementos aquecedores; F) Càmara da amostra; G,H) Isolantes térmicos para a tampa; I) Tampa; J) Entrada do termopar (cobre-constantan); K) Entrada do liquido refrigerador. 


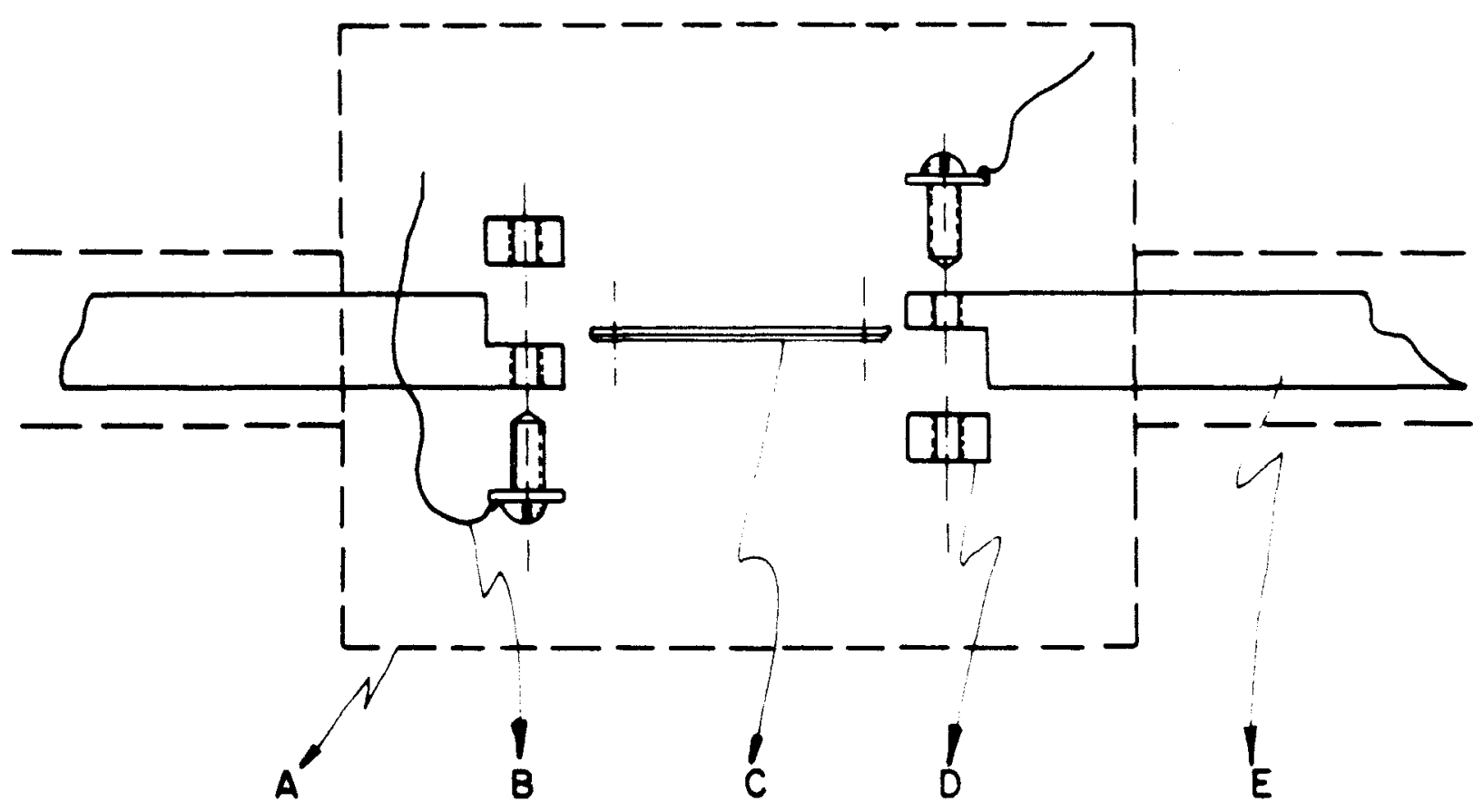

Figura III.5 - Sistema de suporte da amostra no criostato.

$\mathrm{Na}$ figura esquematiza-se a disposição da amostra dentro do criostato: A) Criostato; B) Ligação elétrica; C) Amostra com eletrodos deposi tados; D) Porca e parafusos metálicos; E) Braços suporte de Teflon. 


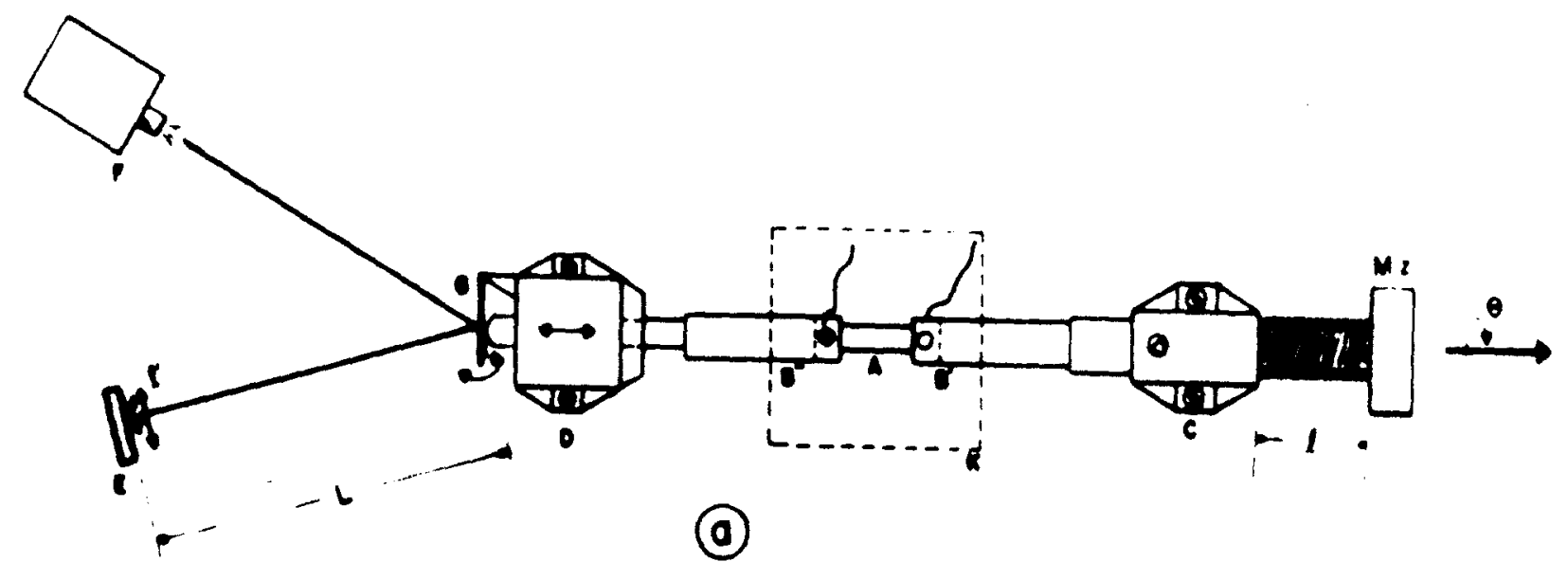

Figura III.6 - Sistema de aplicação da deformação.

A amostra (A) é fixada nos braços suporte (B). Um dos braçossuporte $\left(B^{\prime}\right)$ pode ser movido ao longo do eixo e mantido numa determinada pos $\underline{1}$ ção por um sistema de parafusos concêntricos (C). 0 outro braço suporte (B")é acoplado ao transdutor (D) que está recebendo um sinal de $20 \mathrm{~Hz}$ e assim apli ca à amostra uma tensão deformativa senoidal nessa mesma frequéncia. 0 ponto luminoso, no papel milimetrado (E) procedente da fonte de luz coerente $(F)$ é refletido no espetho $(G)$, permanecerā na posição de "não tensão" enquanto a amostra se encontrar livre de qualquer tensão deformativa. No momento em que os parafusos em (C) fizerem com que o braço-suporte ( $B^{\prime}$ ) se desloque, a amos tra estará submetida a uma tensão deformativa constante; o braço ( $B^{\prime \prime}$ ) se des locarā uma distāncia equivalente à do $\left(B^{\prime}\right)$ e o espelho $(G)$ acompanhará este movimento fazendo com que o ponto luminoso em (E) ocupe uma nova posição.Quan do 0 transdutor receber 0 sinal de $20 \mathrm{~Hz}$, a amostra será submetida a uma ten são deformativa senoidal nesta frequencia e o espelho acompanhará esta vibra ção fazendo com que o ponto luminoso em (E) oscile em tôrno do ponto de ten são constante. 
Teflon é encaixado ao transdutor eletromagnético, o qual aplica uma tensão de formativa senoidal à amostra. Ambas as tensões são qualitativamente observa das por mejo da deslocação, num papel milimetrado, de um ponto luminoso refle tido num espelho e procedente de uma fonte de luz coerente (Apéndice II).0 es pelho, por estar encostado no eixo do transdutor eletromagnético, vibra com a mesma frequēncia deste. A localização da fonte e do papel milimetrado são co nhecidas. Desta maneira e possivel detectar qualquer perda da tensão aplica da.

Na Figura III.7, apresenta-se a fotografia de uma amostra pronta para ser colocada no criostato.

A Figura III.8, é uma fotografia que mostra o criostato para a montagem e medição das amostras.

A Figura III.9, ē uma fotografia na qual mostra-se o sistema de parafusos concêntricos aplicadores da tensão constante, e a fonte de luz coe rente. Nota-se também, o medidor digital de temperatura, e o oscilador que en contra-se atrās do criostato.

A Figura III.10, é também uma fotografia, a qual mostra o sistema em geral.

A frequência utilizada para que o transdutor eletromagnético apli que uma tensão senoidal, foi de $20 \mathrm{~Hz}$, jā que os efeitos ressonantes eram mí nimos por volta deste valor.

Fèz-se uso de uma técnica modular para construir o eletrōmetro (15). Os estāgios de baixo nível, com alta impedāncia de entrada, tinham blin dagem eletrostática, e ligações coaxiais conduziam o sinal à amostra.

No início de uma série de medições era feita a calibração, a qual não tinha necessidade de ser feita de novo.

A precisão do sistema é de $30 \%$, e a sensibilidade é de $\pm 10^{-13}$. Coutombs. 


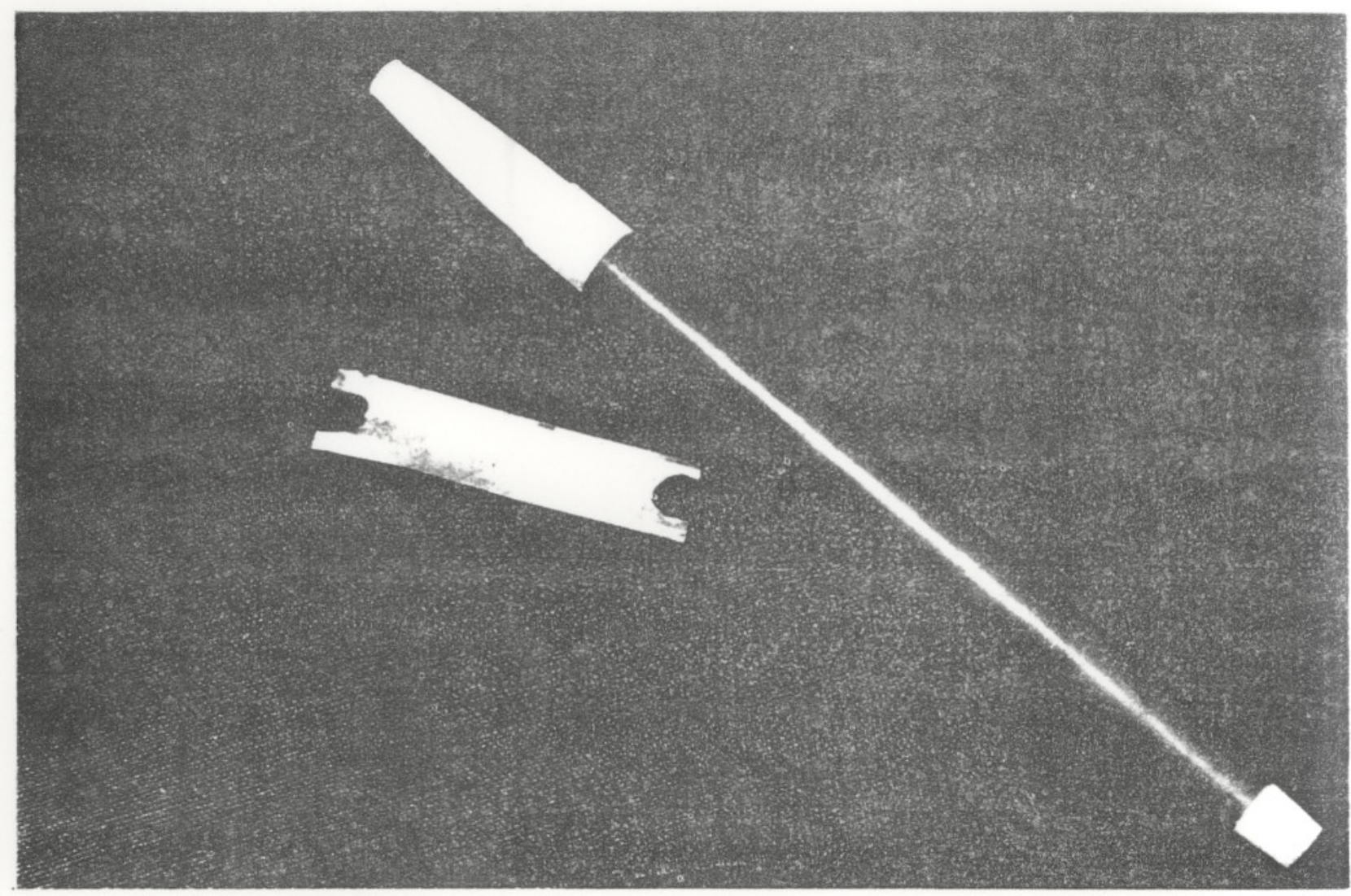

Figura III.7 - Fotografia de amostra pronta para ser colocada no criostato.

Pode-se observar o eletrodo de aluminio depositado e que cobre a superfície inteira. 0 corte è para evitar contato com o parafuso que segura a porca no braço-suporte. As dimensões características são $(50 \times 8 \times 0,05) \mathrm{mm}$. 


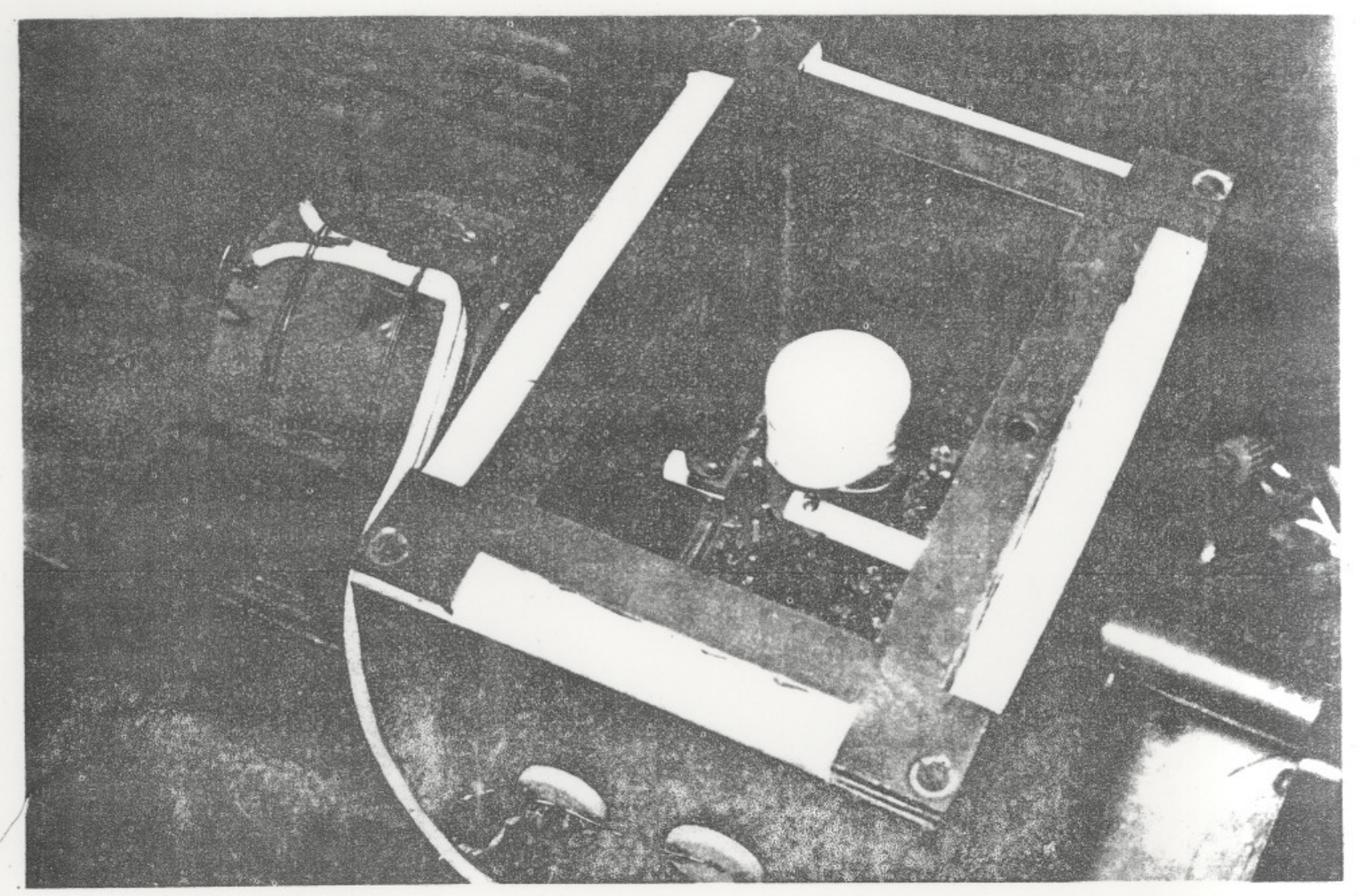

Figura III.8 - Criostato para o controle das condições ambientais durante medição do efeito piezoelétrico de tensão em filmes.

Nota-se os braços-suporte de Teflon e porcas metālicas

para contato elétrico. 0 transdutor eletromagnético, à esquerda, aplica uma tensào mecânica senoidal. A direita, observa-se parte so sistema de parafusos concên tricos para a aplicação de uma tensão mecânica constante. Nota-se, tambēm, o orifício para a colocação do líquido refrigerante. 


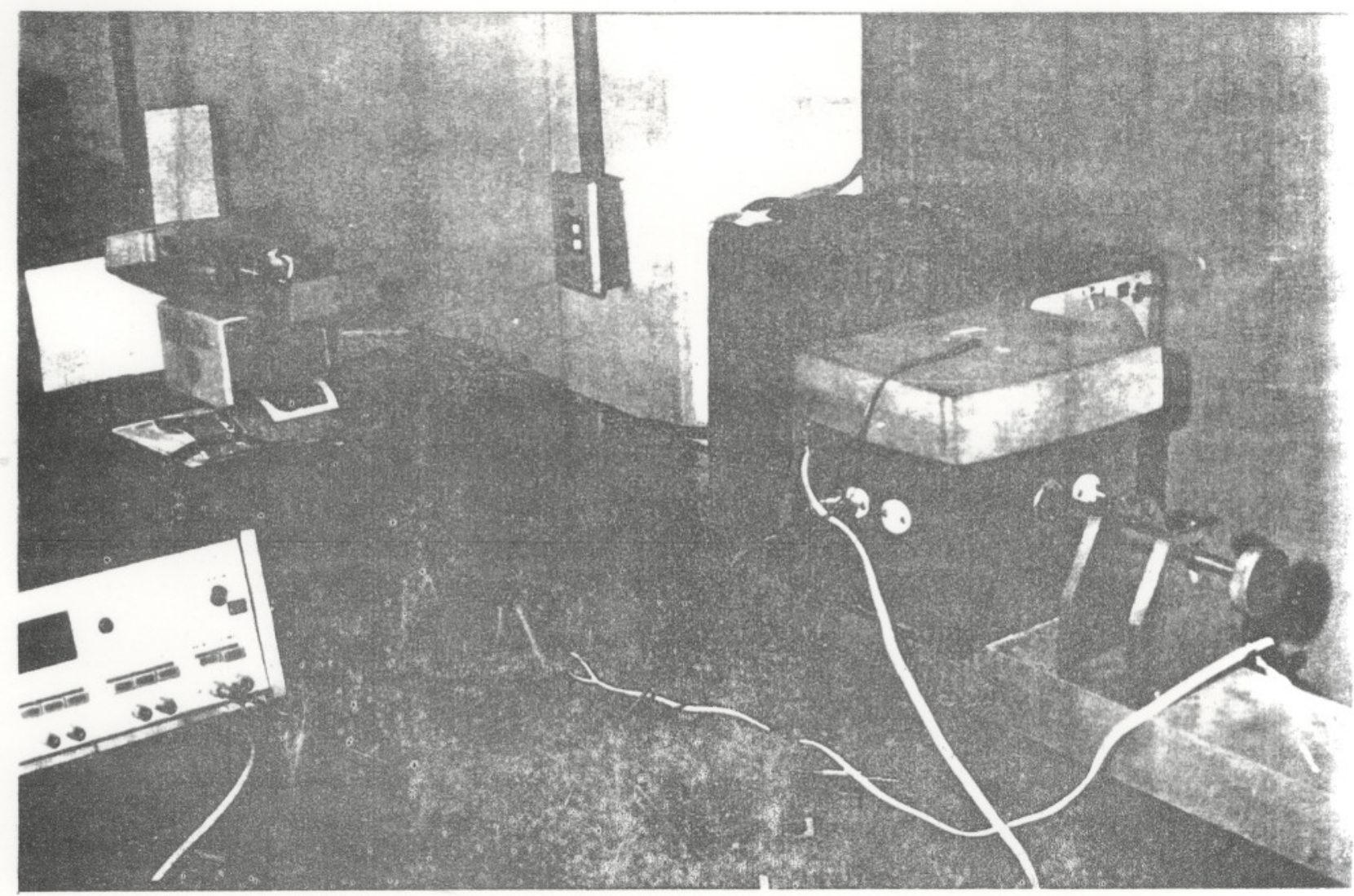

Figura III.9 - Vista do sistema de medição de temperatura e de tensão mecâni ca.

Mostra-se o sistema de parafusos concêntricos para a aplicação da tensão mecânica constante. Nota-se o medidor digital de temperatura, e a fonte de luz coerente. Parcialmente coberto pelo criostato, pode-se observar o oscilador que alimenta o sistema. 


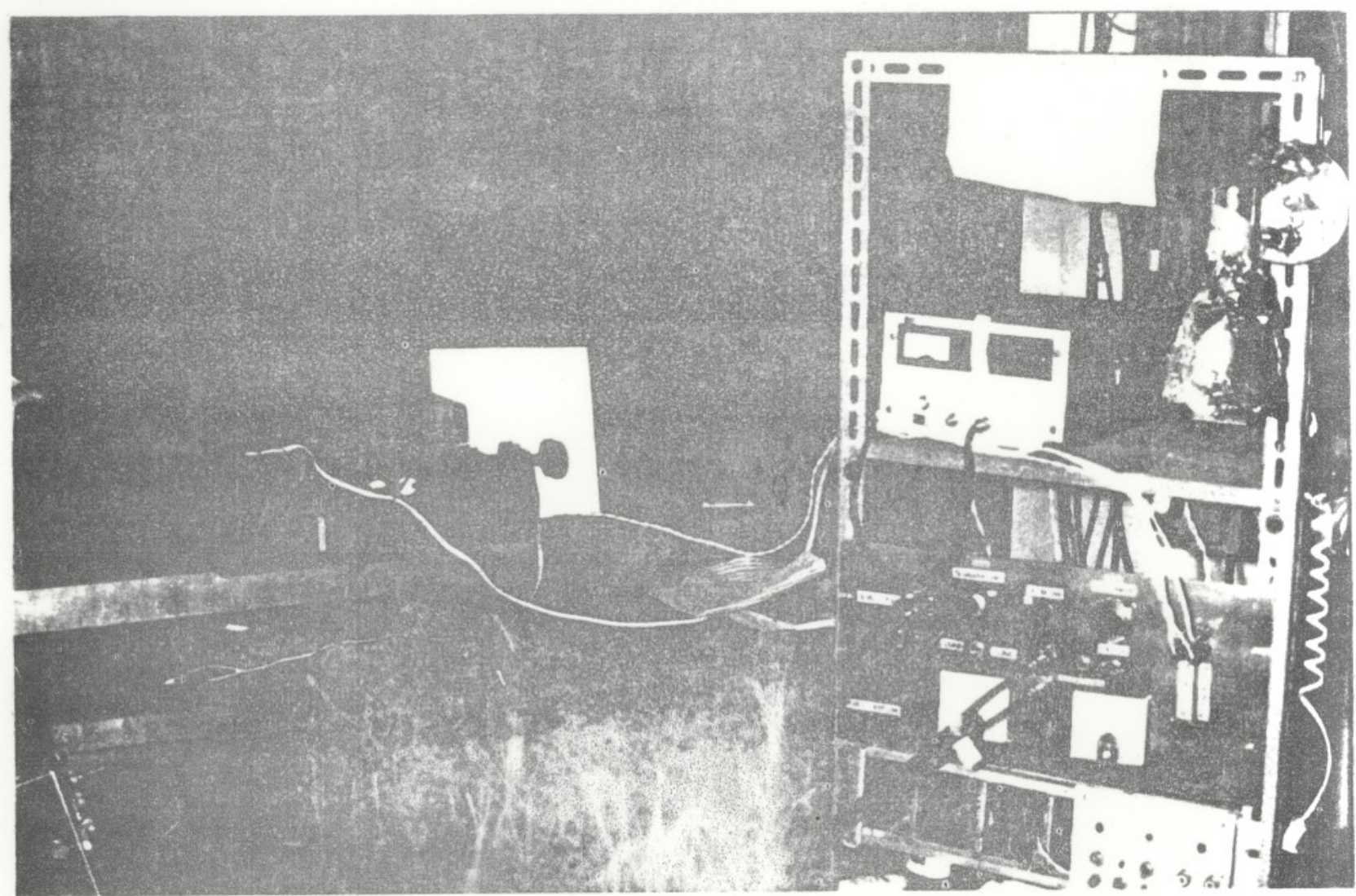

Figura III.10 - Visão geral do eletrōmetro diferencial.

Observa-se a fonte-DC, chaves e potenciōmetros, e circuitos impressos. Os cabos coaxiais vão diretamente aos eletrodos da amostra. 


\section{III.3 Considerações Experimentais}

Considerando, novamente, a Figura III.1, observa-se que (V) $\bar{e}$ a tensão elétrica aplicada ao transdutor, e $\left(\theta^{1}\right)$ e $\left(\theta^{\prime \prime}\right)$ são as frações, desta tensão, dadas pelos divisores resistivos, e que vão dar um nulo nos galvanôme tros através da capacitāncia $(C)$ e a resistēncia $(R)$, respectivamente. Em con sequēncia, considerando que $\omega \bar{e}$ a frequēncia angular do oscilador, as cargas elētricas que cancelariam às cargas geradas na amostra, estariam dadas por

$$
\begin{aligned}
& 2^{\prime}=\theta^{\prime} C V \\
& 2^{\prime \prime}=\theta^{\prime \prime} \frac{V}{\omega R}
\end{aligned}
$$

A incorporação de w nas cargas de cancelação, conjuntamente com o fato de os eletrodos efetivamente cobrirem as āreas (A) da amostra, e que, as dimensões ao longo da direção de medida da polarização são muito menores que as dimensões que determinam a ārea $A$, garantem que a amostra encontra-se em condição de campo elétrico nulo, durante todo o ciclo da força aplicada. Esta condição é essencial na determinação dos coeficientes de piezoeletricidade de tensão, (Equações 1 e 4 ).

Se a condição nula assegura que não hã tensão elétrica na amos tra, então nem a capacitância e nem a resistência, da amostra, e nem a sensi bilidade do galvanōmetro enfluenciam a medida (15)

Sendo que a força $(F)$ gerada pelo transdutor è proporcional à cor rente aplicada e à tensão elétrica, tem-se,

$$
F=\alpha^{-1} V
$$

onde $\alpha \overline{\mathrm{e}}$ a constante do transdutor (Apendice I).

A relação entre a carga (2) gerada na amostra, e a polarização piezoelētrica $(P)$, è dada por, 


$$
P=\frac{3}{A}
$$

Similarmente, considerando-se a largura e a espessura da amostra como $a$ e $b$ respectivamente, a tensão mecânica é expressa como

$$
T=\frac{F}{a b}
$$

Pode-se, assim, empregar a definição do coeficiente de piezoele tricidade de tensão $(d=P / T)$, lembrando-se que $d$ é uma quantidade complexa $\left(d=d^{\prime}-i d^{\prime \prime}\right)$,

$$
\begin{aligned}
& \left.d^{\prime}=\theta^{\prime}\left(\frac{a b}{A}\right) \mid \alpha c\right), \\
& d^{\prime \prime}=\theta^{\prime \prime}\left(\frac{a b}{A}, \frac{a}{\omega R}\right) .
\end{aligned}
$$

No capitulo seguinte, apresentam-se os resultados das medições dos coeficientes de piezoeletricidade de tensão nos polímeros jā mencionados. A temperatura foi mudada entre $=1509 \mathrm{C}$ até $+1009 \mathrm{C}$. A força aplicada senoidal mente foi de $7,5 \mathrm{gr}$. força, pico a pico. A deformação típica das amostras foi de 5 um. Os valores das constantes na equação (19) foram:

$$
\begin{aligned}
& C=10^{3} \mathrm{pF}, \\
& R=10 \mathrm{M} \Omega
\end{aligned}
$$

$\alpha$ (constante do tradutor) $=2,7 \mathrm{Volts} /$ Newton,

$\omega$ (Frequēncia angular, $2 \pi 6)=125,66 \mathrm{rad} / \mathrm{seg}$. 
C A P I T ULO IV

Resultados 
IV- RESULTADOS

Os gräficos que seguem, mostram em sintese as medições feitas do coeficiente piezoelétrico de tensão (d) obtido para os diferentes materiais mencionados no capitulo anterior.

A Figura IV.1, mostra os componentes ( $\left.d^{\prime} e d^{\prime \prime}\right)$ da constante piezo elētrica de tensão, para vārios filmes de polímeros, induzida pela aplicação de um campo elétrico d.c. Observou-se uma boa linearidade entre as constantes piezoelétricas e o campo elétrico. Para um valor do campo elétrico de $10^{6}$ volts/metro, o valor de d' para o Poli (Fluoreto de Vinilideno) (PVF 2 ) $\bar{e}$ de $7 \times 10^{-14}$ coulomb/newton. Este é um valor pequeno comparado com a constante piezoelétrica dos cristais (para quartzo é $d=2 \times 10^{-12}$ coulomb/newton), e também é pequeno comparado com o valor publicado para o coeficiente piezoelé trico do eletreto de PVF $2, d^{\prime}=7 \times 10^{-12}$ coulomb/newton. Jā a rigura IV.2, mostra os valores observados, colocados em escala logaritmica.

A Figura IV.3, mostra relações similares entre os componentes $d^{\prime}$ e d" e o campo elétrico para a amostra de Poli (Cloreto de Vinila) (PVC) com tratamento em diferentes temperaturas. Para evitar que o filme se tornasse um eletreto, o campo d.c. teve o seu sinal invertido para cada medição.observouse uma boa linearidade para $d^{\prime} e d^{\prime \prime}$, em todas as temperaturas utilizadas.

A Figura IV.4, mostra a dependēncia da temperatura para $d^{\prime}$ e $d^{\prime \prime}$ do PVC, com um campo d.c. constante de $2 \times 10^{6}$ volts/metro. Ambos os $d^{\prime} e d^{\prime \prime}$ aumentam notavelmente perto da temperatura de transição vítrea $(\simeq 8090)$. A condutividade d.c., determinada simultaneamente com as medições piezoelétri cas, também aumentam nas mesmas temperaturas.

A Figura IV.5, mostra a dependēncia de $d^{\prime} e d^{\prime \prime}$ no campo d.c., me dida na temperatura ambiental, e para a mesma amostra de PVC, antes e depois do aquecimento. A curva (a) é para uma amostra nova antes do aquecimento. 


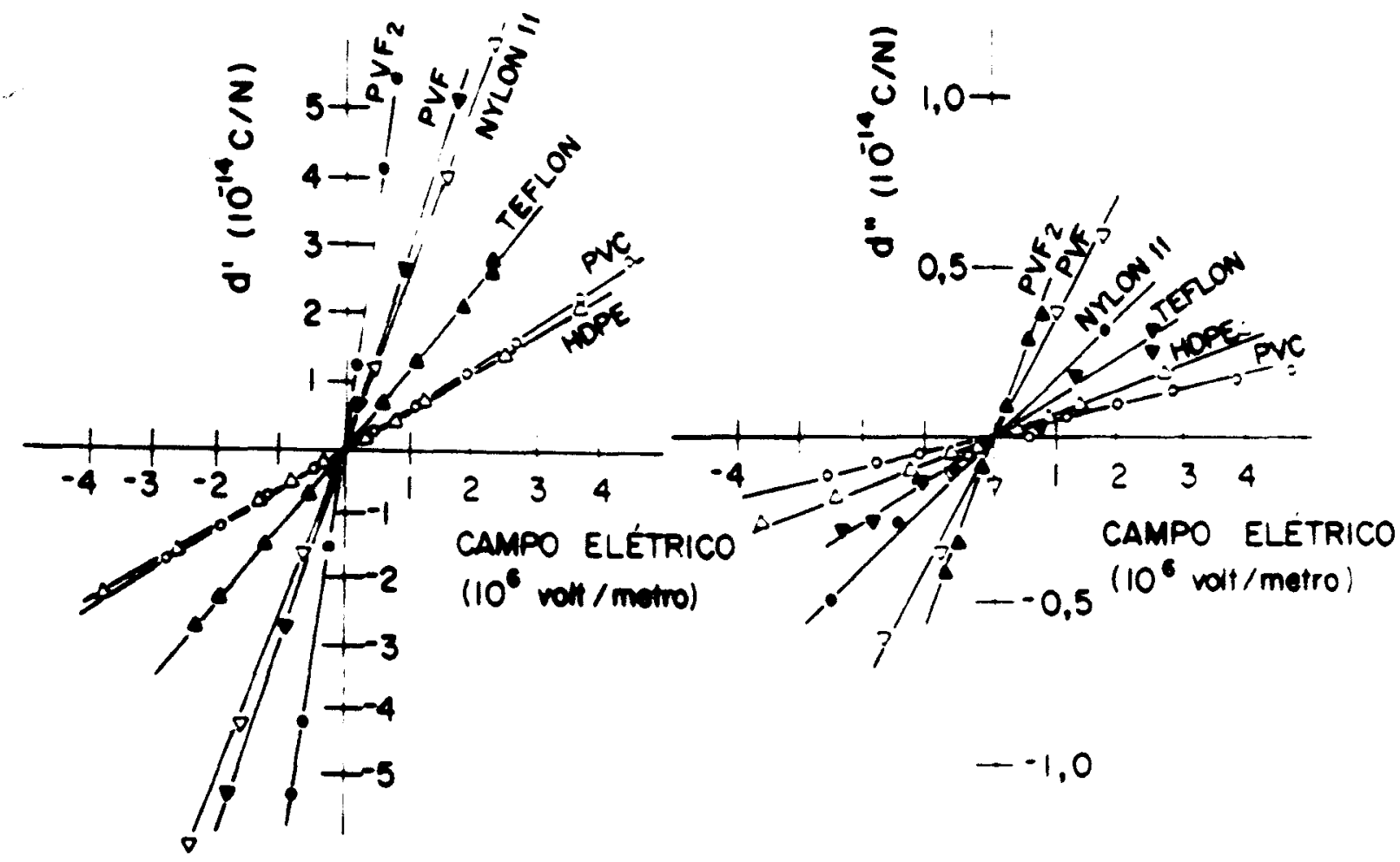

Figura IV.1 - Os componentes : real e imaginārio da Constante Piezoelétrica de Tensão

Os componentes real e imaginārio da constante de piezoeletrici dade de tensão $d=d^{\prime}-i d^{\prime \prime}$, para varios tipos de filmes poliméricos, induzi da pela aplicação de um campo elétrico d.c. constante. 


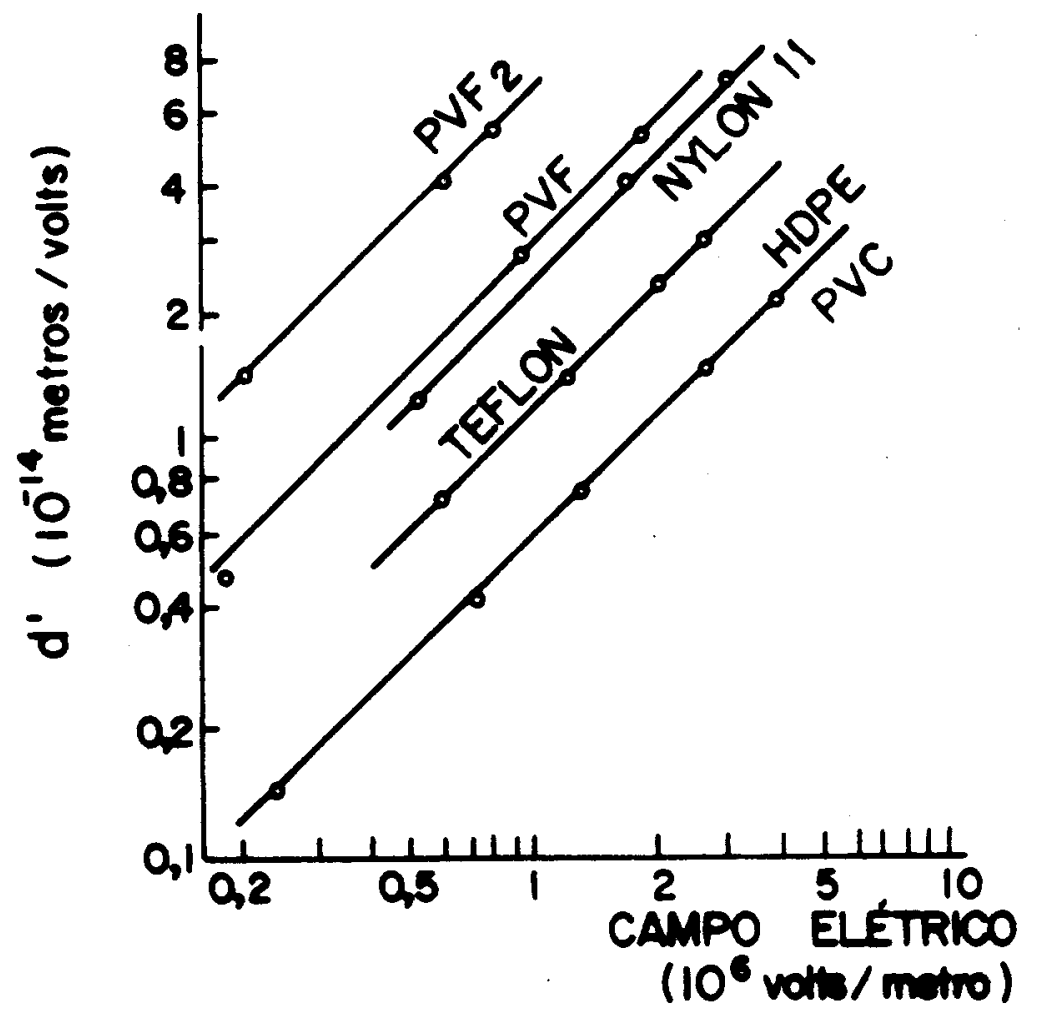

Figura IV.2 - Piezoeletricidade induzida pelo campo elétrico.

A inclinação das curvas mostra a linearidade do efeito, como também mostra que o coeficiente de proporcionalidade é maior para as substān cias polares. 


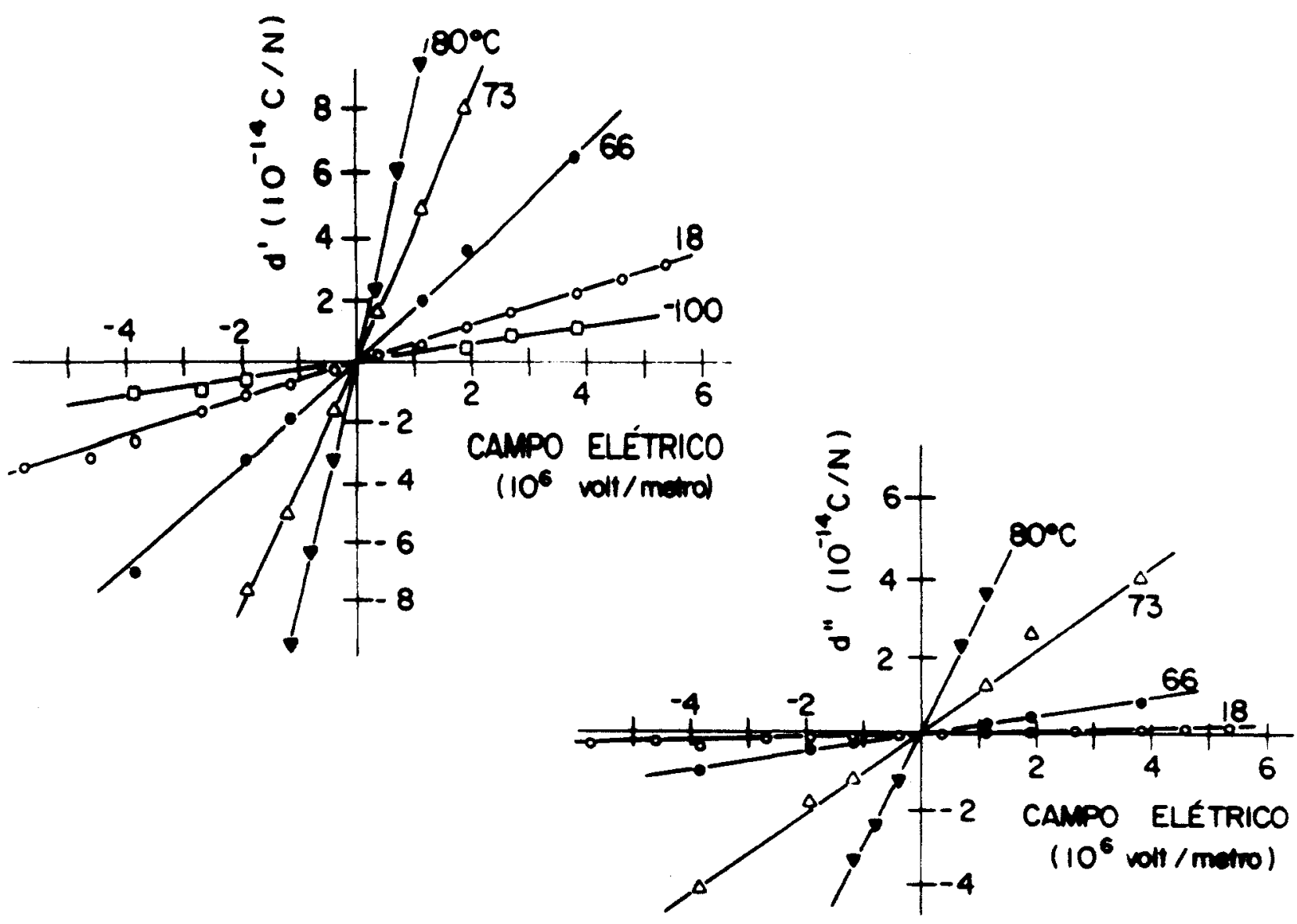

Figura IV.3 - Os componentes da piezoeletricidade de tensão, $d=d^{\prime}-i d^{\prime \prime}$, in duzida pelo campo elétrico, para um filme de Poli (Cloreto de Vinila) em vārias temperaturas. 


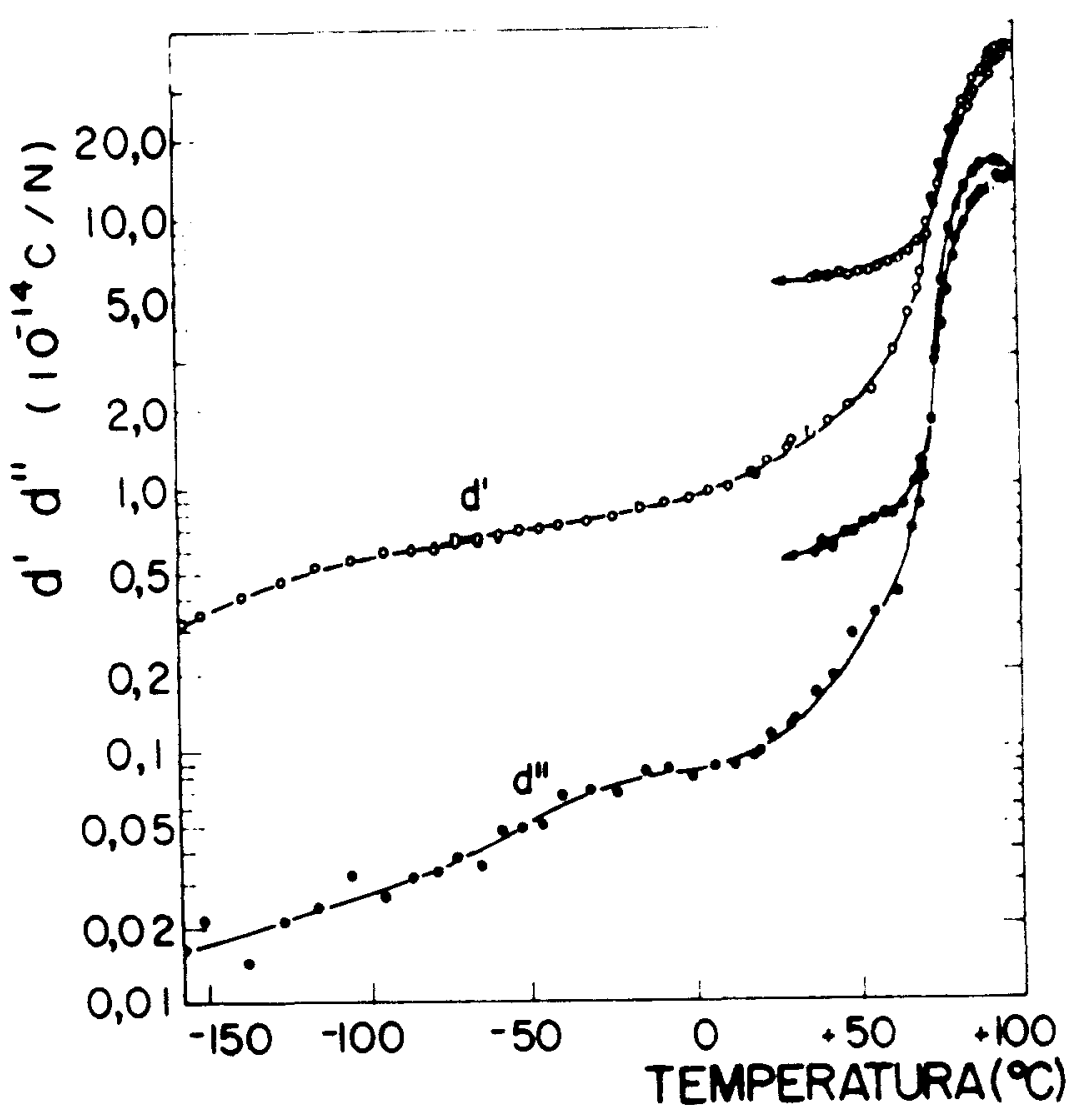

Figura IV.4 - Dependência da temperatura

A dependēncia da temperatura dos componentes $d^{\prime} e d^{\prime \prime}$ para 0 P $\underline{O}$ $1 i$ (Cloreto de Vinila), com um campo elétrico d.c. constante de $2 \times 10^{6}$ volts/ metro. As curvas de resfriamento diferem das curvas de aquecimento jā que a amostra conserva uma polarização permanente quando resfriada sob um campo elé trico aplicado. 


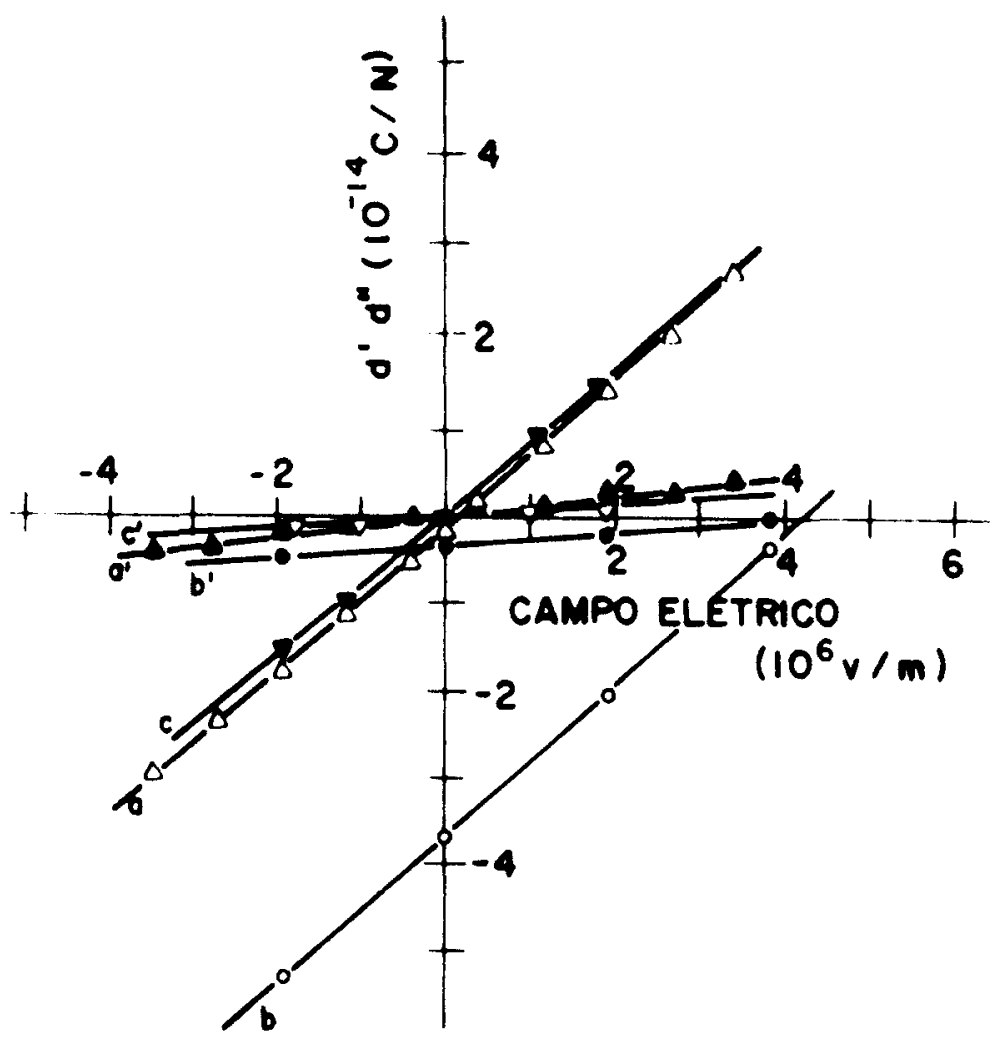

Figura IV.5 - Os componentes da piezoeletricidade de tensão induzida pelo cam po, em uma amostra de Poli (Cloreto de Vinila), depois de um tratamento térmico.

As curvas a e a' mostram que a amostra original tinha uma peque na polarização residual. As curvas b e b' mostam a polarização retida pela amostra depois de um aquecimento a $959 \mathrm{C}$ e consequente resfriamento com um cam po elétrico aplicado de $-2 \times 10^{6}$ volts/metro. As curvas $c$ e $c^{\prime}$ demonstram 0 efeito de neutralização devido ao resfriamento de $800 \mathrm{C}$ até o ambiente, com os eletrodos em curto-circuito. Estas medições foram feitas numa temperatura constante de $200 \mathrm{C}$. 
Pode-se ver que a piezoeletricidade induzida é relacionada linear mente ao campo d.c.. 0 fato que a linha não passe pela origem, indica que a amostra jā tem uma pequena polarização residual presente. A curva (b) resultou de analisar a amostra após resfriamento de 959̣ até a temperatura ambiental , similar ao tratamento mostrado na Figura I1.2; esta curva mostra que com um campo d.c. nulo a amostra apresenta um valor considerável para a piezoeletri cidade, ou seja que a amostra tenha ganho polarização residual, Na sequencia os eletrodos, nas fases da amostra, foram colocados em curto-circuito e a amostra tratada termicamente a $750 \mathrm{C}$, durante a noite. Na curva (c) pode-se ob servar os resultados das medidações em temperatura ambiental e após o trata mento anterior; nota-se que a polarização residual desapareceu e a amostra despolarizou-se.

As curvas $a^{\prime}, b^{\prime}$ e $c^{\prime}$, da Figura IV.5, mostram os correspondentes dados para $d^{\prime \prime}$. A inclinação das curvas $b^{\prime}$ e $c^{\prime}$ é um pouco menor que a de $a^{\prime}$, a qual indica que a tangente de perda $\left(\tan . \delta_{d}\right)$, para a constante piezoelétri ca, torna-se pequena pelo aquecimento. 
CAPITULO V

Discussão 
V- DISCUSSAO

Nas experiências descritas, aplica-se uma vibração longitudinal $\bar{a}$ amostra, a qual encontra-se sob uma voltagem (V) d.c. entre as suas fases de ārea A. Assim a variação da carga elétrica é induzida pela variação da cạ pacitāncia dada pela deformação da amostra. Esta mudança na capacitāncia em função da deformação, pode ser representada por

$$
\begin{aligned}
\frac{\partial C}{\partial S} & =\frac{\partial\left(\varepsilon C_{0}\right)}{\partial S} \\
& =\frac{\partial \varepsilon}{\partial S} C_{0}+\varepsilon \frac{\partial C_{0}}{\partial S}
\end{aligned}
$$

assim, $C_{0}$ é a capacitância em vācuo para eletrodos iguais, e $\varepsilon \bar{e} o$ coeficien te dielétrico.

Considerando que a ārea aumenta em $\left(1-\sigma_{1}\right) S$, e que a espessura diminue em $\sigma_{2} S$, onde $\sigma_{1}$ e $\sigma_{2}$ são as razões de Poisson respectivas, tem-se que

$$
\frac{\partial C_{0}}{\partial S}=C_{0}\left(1-\sigma_{1}+\sigma_{2}\right)
$$

jā que materiais amorfos tem $\sigma_{1}=\sigma_{2}$, e fazendo $\partial \varepsilon / \partial S=\kappa$, a variação da ca pacitância é dada por

$$
\frac{\partial C}{\partial S}=C_{0}(K+\varepsilon)
$$

Ao aplicar um potencial elétrico constante através da amostra com ārea $A$, e fazendo uso das equações $(6,17$ e 23$)$ tem-se um coeficiente de pie zoeletricidade de deformação representado por

$$
e=E_{0}(K+\varepsilon)
$$


Da mesma maneira, considerando as equações ( 9 e 24) tem-se um coe ficiente de piezoletricidade de tensão representado por

$$
d=E_{0}(K+\varepsilon) s
$$

onde s é a constante elástica de "compliance" e $E_{0} \bar{e}$ o campo elétrico constan te, resultado que pode ser observado na Figura IV.2.

observando a linearidade de $d$ em relação ao campo elétrico $\left(E_{0}\right)^{*}$ obtem-se que

$$
2 \gamma=(k+\varepsilon) s
$$

- qual mostra uma combinação entre a dependēncia na deformação do coeficiente dielétrico e as forças elétricas geradas no dielétrico; ambas dão efeitos de deformação quadraticamente dependentes do campo elétrico ${ }^{(25)}$.

Nas Figuras (IV.1 até IV.5), a inclinação das linhas entre $d e E_{c}$ indica os valores $(K+\varepsilon) s$, uma quantidade que envolve à constante de ele trostição $(K)$, à constante dielétrica $(\varepsilon)$, e à constante elāstica de "complí ance" (s).

A Figura IV.I indica que o valor de $d^{\prime} / E_{0}$ para várias classes de polímeros é da ordem dos $10^{-20}$ metros ${ }^{2} /$ volt $^{2}$. Supondo que os valores tipi $\cos ^{(26)}$ para $k, \varepsilon$ es $s$, tem-se que $(k+\varepsilon)=3 \times 10^{-11}$ farad/metro, $c=3 \times 10^{9}$ newtons $/$ metro ${ }^{2}$, e $(k+\varepsilon) / c \simeq 10^{-20} \mathrm{farad} /$ newton, os quais estão dentro da ordem dos valores observados.

* Cap. II, pp. 11: Coeficente de piezoeletricidade induzido pelo campo elé trico constante $\left(E_{0}\right) \bar{e}$ proporcional ao campo elétrico $d=2 \gamma E_{0}$. 
A Figura IV.2 mostra os valores observados da piezoeletricidade induzida pelo campo elétrico, colocados em escala logarítmica. Nota-se que 0 coeficiente da piezoeletricidade varia proporcionalmente ao campo aplicado, como é descrito na equação (25). Os materiais polares que tem maiores coef $\underline{i}$ cientes dielétricos tais como PVF 2 e PVC apresentam maior constante de propor cionalidade. Quando a polarização residual $\bar{e}$ introduzida por um prolongado processo de polarização, como em PVF $_{2}$, a amostra apresenta uma maior piezoele tricidade, a qual persiste ainda depois de ter retirado o campo d.c.

Assim, o método aqui descrito para medir a piezoeletricidade indu zida pe lo campo, dá informação sobre as propriedades dielétricas e elásticas dos polímeros. Ignorando-se a constante de eletrostição $k$, a constante de pie zoeletricidade aparente determina a razão de $\varepsilon$ para s, ou seja o produto de $\varepsilon$ e a constante elāstica de "compliance" s. Considerando que $\varepsilon$ e s são quantida des de relaxação nos polímeros, então d deve também ser uma quantidade relą xante. 0 aumento de $d^{\prime} e d^{\prime \prime}$ nas altas temperaturas, como se mostra na figura

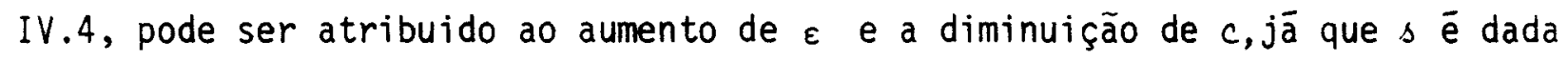
por 0 inverso da constante de rigidez elástica c. Este aumento também pode ser atribuido em parte, a um possivel aumento no grau de cristalinidade do polímero e a um pequeno alinhamento das cadeias poliméricas.

Espera-se que a tangente de perda piezoelétrica, $\tan \delta_{d}$, seja a soma da tangente de perda dielétrica, $\tan \delta_{\varepsilon}$, e a tangente de perca elástica $\tan \delta_{s}{ }^{(24)}$. O valor da $\tan \delta_{d}=d^{\prime \prime} / d^{\prime}$, na ordem de $10^{-1}$, é obtido a partir das Figuras IV.1 e IV.3. Jā que a ordem da $\tan \delta_{\varepsilon}$ e $\tan \delta_{s} \bar{e}$ de $10^{-2}$, o valor observado de $\tan \delta_{d}$ deve ser a soma dos dois. 
C A P I TULO

Conclusões 
VI- CONCLUSÕES

Com base no apresentado, podem-se estabelecer as conclusões se guintes:

0 método, descrito no capitulo III, para medir a piezoeletricidade induzida pelo campo dā uma informação combinada das propriedades elétricas e elásticas dos materiais, no caso específico, dos polímeros sintéticos.

0 aumento de $d^{\prime} e d^{\prime \prime}$ nas altas temperaturas, como observado na $F \underline{j}$ gura IV.4, pode ser atribuido ao aumento de $\varepsilon$ e à diminuição de $c$.

A piezoeletricidade aparente é maior em polímeros polares, como o $\mathrm{PVF}_{2}$ e PVC, do que em polỉmeros não polares, como o Teflon e o polietileno.

Ao induzir polarização residual, na amostra, por meio de um pro cesso prolongado de polarização, a piezoeletricidade obtida é maior, e persis te depois de retirar o campo d.c. aplicado. 
C A P I T ULO VII

Sugestões para Trabalhos Futuros 
VII- SUGESTOES PARA TRABALHOS FUTUROS

Estudo de amostras preparadas com diferentes graus de cristalini dade, visando a elaboração de um possivel método de determinação do grau de cristalinidade em polímeros através do efeito piezoelétrico induzido pelo cam po elétrico.

Estudo de amostras condutoras (eq. gelatina, colágeno, e outros materiais orgânicos naturais), fazendo uso da capacidade de detecção da cor rente de condução que o aparelho tem.

Estudo de filmes poliméricos irradiados com um feixe de elétrons, aproveitando a existência de um acelerador linear " $(8 \mathrm{MeV})$ " no Departamento. Estudo de materiais compostos: polìmero-cerâmica. 
Apendices

e

Bibliografia 


\section{APENDICE}

\section{A.1 Constante do Transdutor}

Para poder obter o valor do coeficiente piezoelétrico segundo a equação (19), se faz necessārio conhecer a constante $(\alpha)$ do transdutor. Com este objetivo se faz a seguinte experiência: situando o transdutor com o seu eixo na vertical Figura (A.1.a), adicionaram-se vārios pesos conhecidos a um suporte especial (M), e o deslocamento de um ponto luminoso em (P), gerado por uma fonte de luz coerente $(L)$, è cancelado pela aplicação de uma corrente, por meio de uma fonte $(V)$, e lida num amperimetro $(A) ;(E)$ forma parte do ele trōmetro diferencial da Figura (III.3).

Com os valores assim obtidos, Figura (A.1.b), e utilizando um fa tor de conversão ( $1 \mathrm{Kgf} .=9.806$ Newtons), obtem-se a magnitude da constante $(\alpha=2,7 \mathrm{Volts} / \mathrm{N})$. 

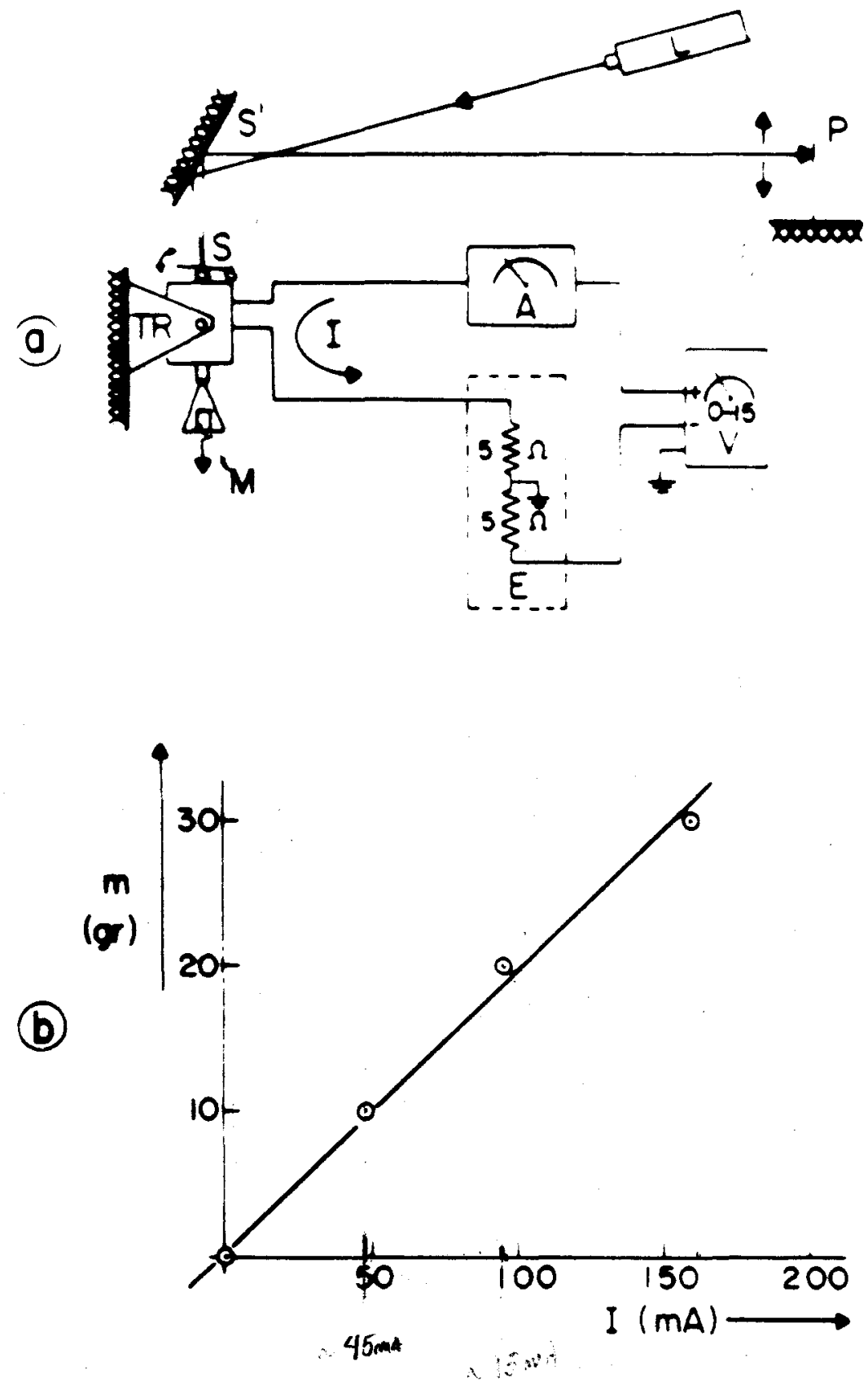

Figura A.1 
Figura A.1 - Determinação da constante do transdutor.

Na Figura mostra-se a montagem experimental utilizada para a de terminação de $\alpha$ : a) 0 transdutor (TR) em posição vertical com porta pesos (M) e espelho (S). O feixe de luz coerente segue a trajetōria LS'SS'P. Os desloca mentos da posição nula do ponto luminoso em (P) são cancelados pela aplicação de uma corrente (I), com fonte em (V) (Heathkit, 0-15V) e monitorada por um amperímetro (A) (Keithley-602), e que passa por uma resistência de $5 \Omega(E)$, que forma parte do eletrōmetro diferencial (Fig.III.3), ao qual o transdutor encontra-se ligado. b) os dados obtidos são mostrados no grāfico.Considerando um fator de conversão ( $1 \mathrm{Kgf} .=9.806$ Newtons) obtem-se $\alpha=2.7 \mathrm{~V} / \mathrm{N}$. 
A.2 Sistema de Observação da Tensão

Para determinar a deformação aplicada à amostra se faz a experien cia seguinte. A montagem experimental é esquematizada na Figura $(A .2, a)$, os braços suporte ( $B^{\prime}$ e $B^{\prime \prime}$ ) são encostados um no outro. Um feixe de luz coerente da fonte $(F)$, incide em $(E)$ e é refletido até $P$. Qualquer movimento angular

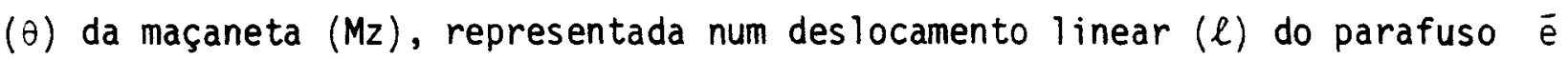
transmitido a B" e amplificado em $P$ como uma deflexão $(\ell$ ') da posição de equi líbrio do ponto luminoso.

Na Figura $(A .2, b)$ apresenta-se a relação $d \ell / d \theta$. Similarmente, a figura $(A .2, C)$ mostra a relação $d \ell^{\prime} / d \theta$. A constante de proporcionalidade en tre as duas relações é dada por

$$
\beta=\frac{(d \ell / d \theta)}{\left(d l^{\prime} / d \theta\right)}
$$

e representa a deformação real que è aplicada à amostra. 0 valor determinado para $\beta$ é de 75 microns para cada centīmetro de deflexão do ponto luminoso, considerando-se $L=54 \mathrm{~cm}$. 


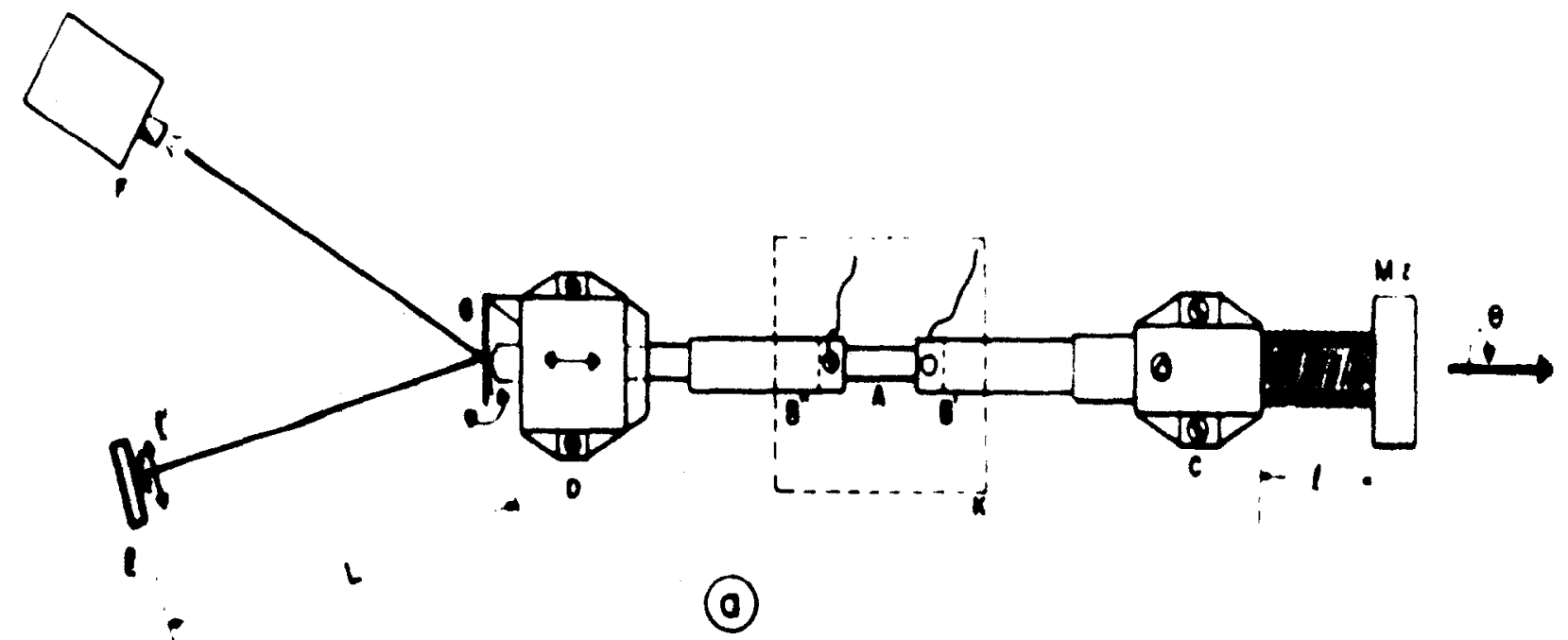

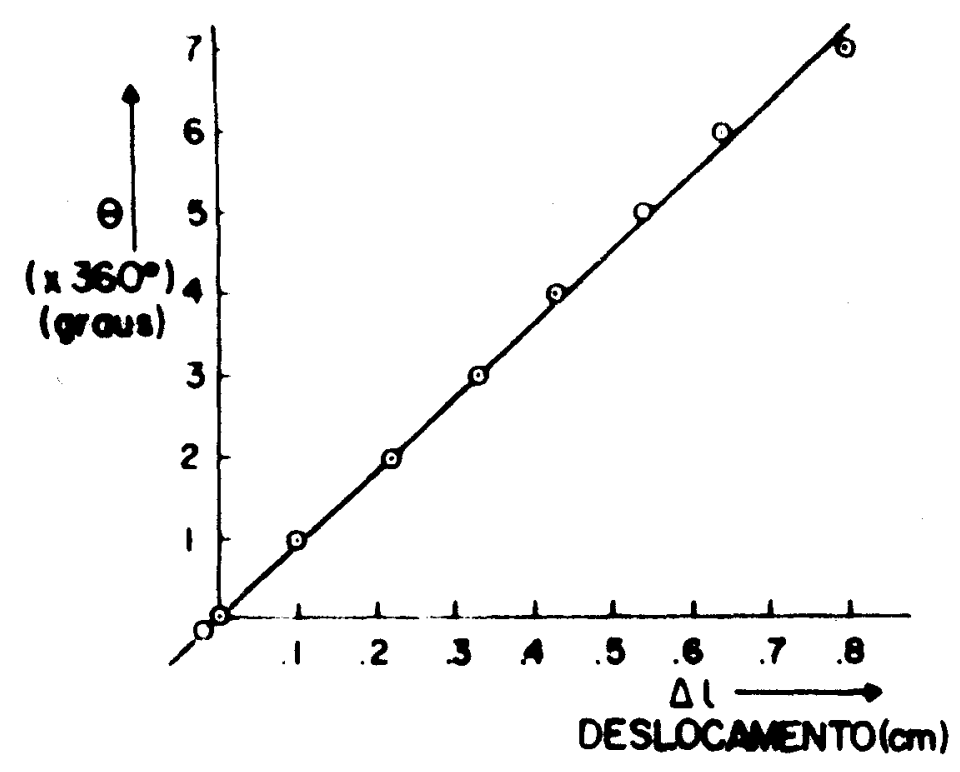

(b)

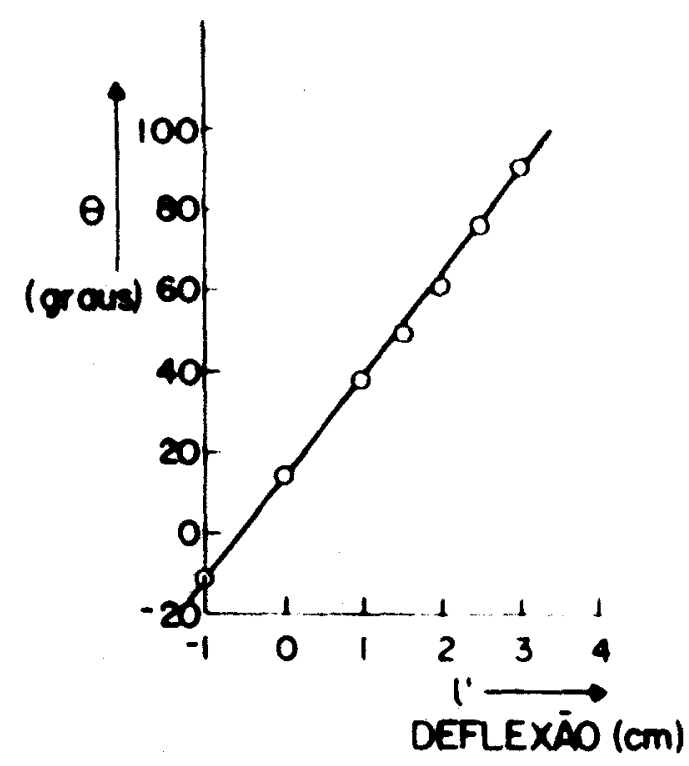

(c)

Figura A.2 
Figura A.2 - Sistema indicador da tensão.

Mostra-se o sistema indicador de tensão: a) Com o braço suporte $B^{\prime}$, qualquer deslocamento linear $(\ell)$ do parafuso é aplicado em um deslocamen to $\left(\ell^{\prime}\right)$ do ponto luminoso em $(E)$. b) $D a \overline{-s e}$ a relação $d \ell / d \theta$, onde $\theta$ é o avanço (em graus) da maçaneta do parafuso $(\mathrm{Mz})$. c) Dá-se a relação $d \ell^{\prime} / \mathrm{d} \theta$. A constan te de proporção $\beta=(d \ell / d \theta) /\left(d \ell^{\prime} / d \theta\right) \bar{e}$ a deformação real exercida na amos tra. $\beta$ tem valor nominal de 75 microns por centīmetro de deflexão do ponto luminoso em $\mathrm{L}=54 \mathrm{~cm}$. 


\section{BIBLIOGRAFIA}

01- BOTTOM, V. E. - "The Theory and Design of Quartz Crystal Units", Mc Murry Press, New York (1968).

02. CADY, W. G. - "Piezoelectricity", Dover, New York (1946).

03- SHUBNIKOV, A. V. - "Piezoelectric Textures". Academy Nauk, S. S. S. R, Moskow (1946). Em russo, citado por Fukada, E., Advances in Biophysics $6,121-155,(1974)$.

04- MARTIN, A. J. P. - "Tribo-electricity in Wool and Hair", Proc. Phys. Soc. $53,186(1941)$.

05- FUKADA, E. and YASUDA, I. - "Piezoelectric Effects in Collagen", Japan Jour. Appl. Phys. 3, 117 (1964).

06- FUKADA, E. and YASUDA, I, - "On the Piezoelectric Effects of Bone", Jour. Phys. Soc. Japan 12, 1158 (1957).

07- FUKADA, E.; DATE, M. and HIRAI, N. - "Piezoelectric Effect in Poly

Methyl L. Glutamate". Nature, London 211, 1079 (1966).

08- FURUKAWA, I.; UEMATSU, Y.; ASAKAWA, K. and WADA, Y. - "Piezoelectricity, Pyroelectricity and Thermoelectricity of Polymer Films", Jour. Appl. Polym. Sci. 12, 2675 (1968).

09- FURUKAWA, T. and FUKADA, E. - "Piezoe lectric Effect and its Temperature, Variation in Optically Active Polypropilene Oxide", Nature,London 221, 1235 (1969).

10- DATE,M.; TAKASHITA, S. and FUKADA, E. - "Temperature Variation of

Piezoelectric Moduli in Oriented Poly T. Methyl L. Glutamate".

Polym. Sci. A.28, 61, (1970).

11- FUKADA, E. - Progress in Polym. Sci., Japan 2, 329 (1971).

12- FUKADA, E. - Jour. Phys. Soc., Japan 10, (1955). 
13- ZIMMERMAN, R. L.; SUCHICITAL, C. and FUKADA, E. - "Electric Field Induced Piezoelectricity in Polymer Film", Jour. Appl. Polym. Sci. 19, 1373 $1379(1975)$.

14- ZIMMERMAN, R. L. - "Induced Piezoelectricity in Isotropic Biomaterial", Biophys. Jour. 16, $1341-1348(1976)$.

15- ZIMMERMAN, R. L. - Tese de Livre Docēncia, Comunicação Particular, I.F.Q. S.C., São Carlos, Brasil (1976).

16- FUKADA, E. - "Piezoelectricity" Private Comunication, I.F.Q.S.C., Brasil (1975) .

17- BAZHENOV, V. A. - "Piezoelectric Properties of Wood". Consultants Bureau, New York (1961), citado em (3).

18- FUKADA, E. - "Recent Research on the Piezoelectricity of Polymers"Private Communication, The Institute of Physical and Chemical Research. Wako. Saitama 351 , Japan.

19- FUKADA, E. - "Piezoelectricity as a Fundamental Property of Wood", Wood Sci., Tech. 2, 299-307 (1968).

20- DAVIS, G. T. and BROADHURST, M. G. - "Piezoelectricity and Pyroelectricity in Polar Polymers", Annals of the International Symposium on Electrets and Dielectrics. I.F.Q.S.C., São Carlos, Brasil, pp. 229 (1977).

21- HAYAKAWA, R. and WADA, Y. - Advan. Polym. Sci. 11, 1 (1973).

22- YAMAgAMI, H. and FUKADA, E. - "A Model Experiment for Piezoelectric Relaxation in Polymers", Polym. Jour. 5,3, 309 - 315 (1973).

23- NYE, J. F. - "Physical Properties of Crystals" Oxford University Press, London (1964).

24- FUKADA, E. and NISHIYAMA, K. - Japan Jour. Appl. Phys. 11, 36 (1972).

25- JEANS, S. J. - "The Mathematical Theory of Electricity and Magnetism" Cambridge University Press, fifth edition reprint, London (1964)pp 179. 
26- Interscience Publishers-"Encyclopedea of Polymer Science and Technology", John Wiley and Sons Inc., New York (1969). 